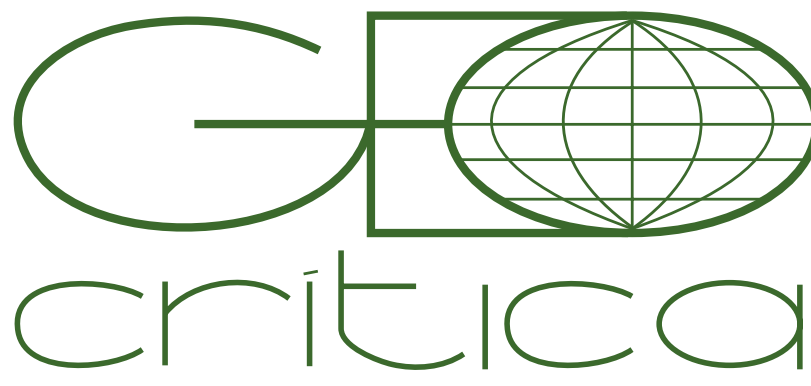

\section{Scripta Nova}

Revista Electrónica de Geografía y Ciencias Sociales Universidad de Barcelona

ISSN: 1138-97

Vol. XXI. Núm. 566

15 de mayo de 2017

\title{
LA MEDIACIÓN COMO ALTERNATIVA. POLÍTICA DE VIVIENDA Y REGULACIÓN DE LA EMERGENCIA HABITACIONAL EN BARCELONA
}

\author{
Tania Herrera Romero \\ Pontificia Universidad Católica del Perú \\ t.herrera@pucp.pe \\ Recibido: 13/10/2016; Devuelto para revisión: 14/12/2016; Aceptado: 2/01/2017
}

Este artículo es parte de una investigación realizada para el Master Altervilles: Alternativas políticas y estratégicas para ciudades y metrópolis de la Universidad de Lyon. Quiero agradecer especialmente a Christelle Morel-Journel (Université Jean Monnet-Saint Etienne) y a Núria Benach (Universitat de Barcelona) por su valioso acompañamiento en diferentes etapas de este trabajo.

\section{La mediación como alternativa. Política de vivienda y regulación de la emergencia habitacional en Barcelona (Resumen)}

Los esfuerzos que despliega la ciudad de Barcelona para enfrentar la emergencia habitacional parecen condicionados por tres elementos que estructuran la política de vivienda: a) la difícil traducción política del carácter social y económico de la vivienda, b) el privilegio concedido por las políticas nacionales a los agentes inmobiliarios-financieros, lo que motiva la precarización de los inquilinos y c) el insuficiente parque público de viviendas, que se traduce en una demanda ciudadana que sobrepasa la capacidad de gestión municipal. Poniendo énfasis en la vivienda bajo régimen de alquiler, nuestro trabajo se propone comprender y explicar cómo regula el Ayuntamiento de Barcelona la política de vivienda y qué posibilidades existen para el despliegue de políticas urbanas alternativas.

Palabras clave: política de vivienda, políticas urbanas alternativas, emergencia habitacional

\section{Mediation as an alternative. Housing policy and housing-emergency regulation in Barcelona (Abstract)}

The efforts of the City of Barcelona to face the housing- emergency context seem conditioned by three elements structuring housing policy: a) the difficulty to translate social and economic attributes of housing into political terms, b) the privilege granted by national policies to real estate and financial agents, motivating the instability of tenants, and c) the insufficient public housing stock that coexists with a citizen's demand that goes further from municipal capacity of management. Emphasizing housing on a rental basis, our work aims to understand and explain how does the Barcelona City Council regulates housing policy and what possibilities exist for the deployment of alternative urban policies.

Key words: housing policy, alternative urban policies, housing emergency 
Uno de los más interesantes debates de los estudios urbanos trata sobre los cambios en la acción pública y en las relaciones entre Estado-central y gobiernos locales. En este contexto, resulta fundamental preguntarse cuál es la mejor escala para contestar la urbanización capitalista de nuestras ciudades y desplegar políticas que induzcan una transformación progresista de la sociedad. Se ha advertido sobre una tendencia a desprestigiar la regulación pública nacional, la cual ha justificado prácticas y narrativas promotoras de la privatización de los servicios municipales ${ }^{1}$. Sin embargo, sostenemos que rechazar ciertos aspectos de la regulación estatal no implica, a priori, la adopción de una actitud en defensa del empresarialismo urbano y la privatización de los servicios ${ }^{2}$. Diversos trabajos de geógrafos críticos en el campo de los urban studies han puesto de manifiesto el activo rol del Estado en la neoliberalización, entendida como un proceso de ejecución del proyecto neoliberal ${ }^{3}$. En tanto proceso, se diferencia del neoliberalismo definido como proyecto político, económico y de reorganización de la sociedad. Este proyecto implica una fuerte intervención del Estado y de los gobiernos locales en la regulación del mercado, a través de la creación de un marco institucional que le sea favorable ${ }^{4}$. Así, el neoliberalismo es un proyecto de regulación con características multiescalares que busca perpetuar la sostenibilidad de la economía capitalista a mediano y largo plazo5.

En los estudios urbanos, se analiza la tesis neoliberal afirmando una identidad crítica en la producción de conocimiento ${ }^{6}$. No obstante, algunos estudiosos señalan los riesgos del empleo extensivo y el abuso de la neoliberalización, el neoliberalismo, $\mathrm{u}$ otros conceptos relacionados que debieran ser cuidadosamente situados en miras a ser más rigurosos en el análisis de los procesos subyacentes a las transformaciones de las políticas públicas, así como de las relaciones entre las diferentes escalas de gobierno $^{7}$. Christelle Morel-Journel y Gilles Pinson sostienen que la omnipresencia (agregación de ideas y acciones de origen diverso en un único macro-proceso) y la omnipotencia (reducción de las causas de ideas y acciones a un único macro-proceso) de la tesis de la neoliberalización acarrea un énfasis en la construcción teórica en desmedro de la producción de datos empíricos que evidencien los diversos rumbos emprendidos por las políticas públicas urbanas ${ }^{8}$.

Un límite clave de la tesis neoliberal es que tiende a reducir todas las políticas públicas al proyecto neoliberal, lo que dificulta la identificación de fuerzas neutralizadoras, o fuerzas capaces de parasitarlo o absorberlo ${ }^{9}$. Esta crítica suele acompañar

$1 \quad$ Horacio Capel advierte también que, en regiones como Cataluña, dichos discursos están acompañados por un sentimiento nacionalista (Capel, 2010, p.180; 2013, p.43).

2 Harvey, 1989

3 Brenner y Theodor, 2002; Peck y Tickell, 2002; Brenner, 2004; Harvey, 2007; Béal, 2010.

4 Jessop, 2002; Harvey, op.cit.

$5 \quad$ Peck et Tickell, op.cit.

6 Béal, op.cit.

7 Ver Morel-Journel y Pinson, 2016; Le Galès, 2016; Storper, 2016

$8 \quad$ Morel-Journel y Pinson, op.cit., p.145

9 Id., p.142-146 
la producción de trabajos que reflexionan sobre el margen de maniobra de los gobiernos locales para llevar adelante políticas urbanas alternativas, es decir, "(...) iniciativas, prácticas o proyectos respaldados por las municipalidades y que buscan organizar un desarrollo urbano que se aleje de los cánones del empresarialismo"10. Siguiendo una definición ideal-tipo, los politólogos Vincent Béal y Max Rousseau caracterizan tales políticas en tres puntos. Primero, son iniciativas realizadas a raíz de las reivindicaciones de los movimientos sociales urbanos, no de recetas impuestas por grupos de expertos. Segundo, el crecimiento económico no es el principio motor de estas políticas. La Administración priorizará, decididamente, limitar el desarrollo desigual. Por último, los recursos de la municipalidad son canalizados principalmente a favorecer a las clases populares presentes en la ciudad antes que a los visitantes y a los grupos privilegiados. Los autores postulan la hipótesis de que "(...) un poderoso vínculo entre la sociedad urbana movilizada y el Ayuntamiento sería una de las condiciones necesarias a la emergencia de estrategias urbanas alternati-

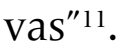

En plena emergencia habitacional ${ }^{12}$, nuestro interés en las políticas urbanas alternativas se focaliza en los instrumentos ${ }^{13}$ que articulan la política de vivienda de la ciudad de Barcelona, tales como el Registro de solicitantes de vivienda protegida y la Unidad Contra la Exclusión Residencial (UCER). El objetivo es comprender y explicar cómo regula la emergencia habitacional el Ayuntamiento de Barcelona y de qué manera las políticas desplegadas son alternativas. Nuestra hipótesis es que la organización de competencias vinculadas a la política de vivienda reserva el monopolio de competencias económicas en manos del Estado y limita el despliegue de políticas urbanas alternativas desde la escala local. Metodológicamente, nos propusimos un camino inductivo con levantamiento de información primaria entre los meses de octubre 2015 y febrero 2016. Nos fue posible identificar tres momentos en nuestro estudio. Inicialmente, hemos consultado información estadística que nos permita

$10 \quad$ Béal y Rousseau, 2014, p.5

11 Id., p.6

12 A la cual definimos como la dificultad de satisfacer de manera sostenible el derecho a la vivienda debido a la inminencia de desalojos y ejecuciones hipotecarias por impagos de alquiler o hipotecas. La "Ley 24/2015 de medidas urgentes para afrontar la emergencia en el ámbito de la vivienda y la pobreza energética" no define qué se entiende por emergencia en el ámbito de la vivienda o emergencia habitacional. Sin embargo, el preámbulo incluye un diagnóstico con cifras de desempleo en Cataluña y referencias al gran problema de los desahucios por impago de hipotecas y de alquileres. Tampoco se encuentra una definición en el informe «Emergencia habitacional en el Estado español», del Observatorio DESC y la Plataforma de Afectados por la Hipoteca (PAH), que ha servido como insumo para la elaboración de la Ley 24/2015.

13 En sociología de la acción pública, un instrumento es “(...) un dispositivo técnico a vocación genérica que porta una concepción concreta de la relación política/sociedad y se sostiene por una concepción de la regulación" (Lascoumes y Le Galès, 2004, p.14). En tanto institución particular, los instrumentos estructuran la acción y la representación colectiva de los problemas sociales, pues privilegian ciertos actores e intereses en la problematización de los temas. De esta manera, “(...) los instrumentos permiten estabilizar las formas de acción colectiva, de hacer más previsible, y sin duda más tangible, el comportamiento de los actores" (Lascoumes y Le Galès, 2012, p.100). El acento en los efectos que producen permite poner de manifiesto los cambios en las políticas públicas y deconstruir la aparente neutralidad de los dispositivos (Lascoumes y Le Galès, 2004). 
generar perfiles demográficos y económicos de los diez distritos de la ciudad de Barcelona con el fin de elegir uno donde realizar nuestro trabajo de campo ${ }^{14}$. En paralelo, realizamos la consulta de documentos oficiales (bibliografía gris) como el Plan de Vivienda de Barcelona 2008-2016, el cual nos brindó información sobre las políticas de vivienda aplicadas por el Ayuntamiento. De esta revisión, conocimos cómo funciona el Registro de Solicitantes de Vivienda Protegida y la atribución de vivienda social, lo cual nos permite profundizar sobre la organización de las competencias en materia de vivienda. Un segundo momento de nuestra investigación -que se traslapa con el primero- incluye el mapeo de organizaciones sociales que trabajan por el derecho a la vivienda. Fue así como conocimos el trabajo de la Plataforma de Afectados por las Hipotecas -PAH Barcelona y decidimos asistir a sus asambleas semanales los días lunes en el distrito de Sants. En estos espacios, escuchamos referencias a los constantes problemas en el distrito de Nou Barris, razón por la cual -y debido a la suma de indicadores que muestran este distrito como uno de los más vulnerables ante la emergencia habitacional- decidimos aproximarnos a la Asociación 500x20 Por el Alquiler Público y Asequible, importante referente distrital en la lucha contra las expulsiones y desahucios. Además de la sobre-representación de problemas de expulsiones en el distrito de Nou-Barris, las sinergias generadas con 500×20 nos convencieron de restringir el ámbito de nuestro estudio, pero no evitamos las comparaciones con otras escalas de análisis. Hemos realizado alrededor de cincuenta horas de observación en asambleas de estas dos organizaciones, además de entrevistas (a profundidad y semi-directivas) a sus activistas. También, entrevistamos a representantes del Ayuntamiento de Barcelona, a investigadores especialistas en vivienda, así como a personas inscritas o en proceso de inscripción al Registro de Solicitantes de vivienda protegida, las cuales abordamos en la Oficina de Vivienda del distrito de Nou Barris ${ }^{15}$. Un tercer momento, paralelo al anterior, incluye la sistematización de la información recogida, es decir, la digitalización de notas tomadas a mano durante las asambleas además de la transcripción (parcial y total) de las entrevistas registradas por el dictáfono (treinta y cinco en total, pues de dos no se obtuvo autorización para grabar).

14 Desde el inicio de la investigación, uno de los objetivos fue acercarnos a los distritos donde habita la población con renta inferior a la media de la ciudad (considerando todos los distritos de Barcelona). Esto implicaba diferenciar espacialmente los barrios donde reside la población con rentas más elevadas, con rentas medias y con renta por debajo de la media. Para realizar esta tarea fue de gran ayuda el trabajo de Bayona (2007) y sus coautores (2012).

15 Algunas personas entrevistadas fueron Antonio Tallada (activista de 500x20 y conseiller de Barcelona-En-Comú por el distrito de Nou Barris), Carme Porta (mediadora de la UCER y ex activista de la PAH-Barcelona), Carolina Recios (conseiller de Barcelona-En-Comú por el distrito de Nou Barris y encargada de hacer el seguimiento a Servicios Sociales), Elena Aragüés (activista de 500x20), Fabiana Valdoski (geógrafa, investigadora especialista en organizaciones sociales en Nou Barris), Jaume Barnada (Departamento de Vivienda-Ayuntamiento de Barcelona), Salva Torres (activista 500x20), Llorenç Núñez (activista PAH-Barcelona), Salva Torres (activista 500x20), Manuel Cubero ( conseiller de Barcelona-En-Comú por el distrito de Nou Barris), Mercè Tatjer (geógrafa, especialista en temas de vivienda), Rosa Tello (geógrafa, especialista en temas de vivienda), Silvia Gimenez (activista y presidenta de 500x20), Socorro Pérez (urbanista, investigadora especialista en vivienda). 
En cuanto a la organización de este artículo, en la primera parte, analizamos la configuración de la política de vivienda a diferentes escalas de gobierno, lo que revela los problemas que acarrea la traducción política del doble componente económico y social de la vivienda. Argumentamos que la organización de las competencias en materia de vivienda limita las acciones del Ayuntamiento a la gestión de situaciones de urgencia. Seguidamente, mostramos cómo la evolución legislativa sobre arrendamientos urbanos entraña la progresiva precarización de los inquilinos. Esta situación promueve la inestabilidad residencial y subordina el derecho a la vivienda a las estrictas exigencias del mercado. Luego, concentramos la atención en la gestión local del parque público de viviendas. Para ello, analizamos la relación entre la insuficiente oferta y la desbordante demanda en plena emergencia habitacional. Finalmente, mostramos que, lejos de buscar evadir responsabilidades, el Ayuntamiento de Barcelona despliega diversas estrategias para proveerse de mecanismos que permitan enfrentar los problemas de vivienda. La creación de la UCER aparece como una herramienta alternativa que se inspira en el trabajo de las organizaciones sociales y, de esta manera, introduce innovaciones en la acción pública local.

\section{La vivienda en España: un derecho social sin reconocimiento económico}

A diferencia de la noción de vivienda, que alude a las características materiales y arquitecturales del espacio donde uno vive, la noción de hábitat implica la realización de necesidades antropológicas elaboradas socialmente ${ }^{16}$. El hábitat desborda la vivienda, porque implica la producción y la transformación del espacio, proceso donde un conjunto de vínculos es creado, tanto al interior como al exterior de la vivienda ${ }^{17}$. Así, es preciso comprender la vivienda en esta doble dimensión: como soporte material y espacio de realización de las necesidades. De manera más general, el acceso a la vivienda representa la inclusión de los individuos a la vida social urbana. El reconocimiento de la ciudadanía, el derecho a la ciudad y a la vida urbana pasan por la domiciliación. Además, la dimensión económica de la vivienda es fundamental; como patrimonio familiar, es una mercancía que puede ser comprada y vendida $^{18}$. En el marco de la producción capitalista de la ciudad, acceder a la vivienda depende largamente del acceso al mercado inmobiliario. De esto, se desprende el vínculo del acceso a la vivienda con la participación de la unidad de convivencia en el mercado laboral ${ }^{19}$.

16 En un bello pasaje de "El derecho a la ciudad", Henri Lefebvre critica la producción capitalista de la ciudad, que reduce las actividades sociales al consumo mercantil. Para él, las necesidades específicas de los seres humanos (necesidad de obra y creación, de simbolismo, de juego, etc.) implican la búsqueda de espacios de encuentros, previstos e imprevistos, fuera de los intercambios mercantiles y de acumulación (Lefebvre, 2009, p.95-96).

17 Paquot, 2005

18 Fijalkow, 2016, p.3

19 Se emplea el término "unidad de convivencia" o "unidad económica de convivencia" para referirse a las personas que comparten una vivienda y están unidas por matrimonio "(...) o por lazos de parentesco de consanguinidad hasta de segundo grado." Fuente: Ministerio de Empleo y Seguridad Social, 2016. 
Esta doble dimensión de la vivienda tiene una difícil traducción en las políticas públicas. En el caso español, el Estado posee las competencias exclusivas para regular en materia económica y, como es un derecho social, la regulación es competencia de las Comunidades Autónomas ${ }^{20}$, quienes pueden ceder la competencia a los Ayuntamientos mediante acuerdos específicos. Dicha separación resalta ante la compleja y burocrática organización de la política de vivienda tanto entre diferentes escalas de gobierno como al seno mismo del Ayuntamiento. El monopolio estatal de las competencias en materia de regulación económica es crucial para comprender la efectividad de los programas y políticas de vivienda efectuadas a escala de los ayuntamientos ${ }^{21}$. El derecho a la propiedad y a la libertad de empresa son dos de los ejes fundamentales en la política económica de España, donde el Estado es responsable del buen funcionamiento y la protección de la economía de mercado ${ }^{22}$. Esto no significa, sin embargo, que el gobierno local no tenga ningún margen de maniobra en la regulación. Con el objetivo de desarrollar proyectos de vivienda, el Ayuntamiento organiza la participación de diversas instituciones tanto públicas como privadas, lo que entraña una superposición de actores que intervienen en la regulación de los problemas vinculados al acceso a la vivienda ${ }^{23}$.

Si las competencias estructurales que permiten actuar en materia económica pertenecen al Estado, otras competencias operacionales y de gestión están en manos de las comunidades autónomas y las ciudades. Éstas pueden hacer convenios a fin de intercambiar responsabilidades precisas. Para Barcelona, por ejemplo, la Carta

20 Artículo 148 de la Constitución Española, relativo a las competencias de las Comunidades Autónomas. Otras competencias reposan en las comunidades autónomas: la agricultura, el acondicionamiento territorial, la asistencia social y la promoción de la cultura. El acondicionamiento territorial implica acciones relativas al urbanismo y a la vivienda, que fueron por primera vez descentralizadas en 1978, luego de varios decenios de dictadura franquista (Id.Ibid). La creación del Instituto Catalán del Suelo (INCASOL) en 1980 representa un momento fundamental en el ejercicio de competencias relativas al urbanismo, pues estará a cargo de planificar y administrar el suelo de propiedad pública. De igual manera, la empresa pública de Administración y Gestión (ADIGSA) complementa el trabajo de INCASOL a través de la gestión de las 60000 viviendas que fueron transferidas a la Generalitat por el Ministerio de Vivienda (Vilanova, 1997; Barceló y Vintró, 2003, p.249). Pero, esta transferencia no ha estado acompañada por la atribución de recursos económicos que permitan el desarrollo de una verdadera política de vivienda pública a escala de las comunidades autónomas.

21 Barceló y Vintró, op.cit., p.195; Vilanova, 1997

22 Betancor, 2008, p.225. A manera de ilustración, en el 2007, es aprobada la Ley de Defensa de la competencia, válida a escala nacional, cuyo objetivo es "la protección del mercado (y) la libre competencia entre los agentes de mercado" (op.cit., p. 227-228). El mismo año, en Cataluña se aprueban tres medidas relativas a la vivienda: el Pacte Nacional per a l'Habitatge, la Ley del Derecho a la vivienda y el Pla Territorial Sectorial de l'Habitatge. El Pacte Nacional hace un diagnóstico de las necesidades en materia de vivienda y representa el reconocimiento político de la necesidad de llegar a acuerdos específicos. En este sentido, es un instrumento que busca dar sostenibilidad a las políticas públicas, al tiempo que afirma la voluntad por trabajar desde diferentes campos y con diversos actores. Entre los firmantes se encuentran promotores públicos municipales, constructores, agentes vinculados al mercado inmobiliario, representantes de gobiernos locales, entre otros. El Pacte es un antecedente inmediato de la Ley 18/2007 (cuya elaboración empezó durante el primer tripartito), pues exige su aprobación (Trilla, s/f: 40-41; Vilanova, s/f: 53). Vemos que la regulación pública se va calibrando -aunque no necesariamente de manera sincronizada- desde diferentes escalas.

23 Barceló y Vintró, op.cit. 
Municipal ${ }^{24}$ aprobada en 1998 por el Parlamento de Cataluña, reconoce un régimen jurídico especial para la ciudad y un régimen legal a los distritos, "(...) concebidos como una pieza fundamental de la organización municipal y de sus entidades territoriales, para la desconcentración de la gestión y para la descentralización de la participación ciudadana" 25 . La Carta opera entonces como una pequeña legislación para la ciudad, y permite a la municipalidad asociarse con la Generalitat de Cataluña a fin de transferir competencias específicas ${ }^{26}$. Esto se hace a través de la creación de consorcis, instituciones que conectan las dos escalas de gobierno y sobre las cuales reposa la gestión de ciertos sectores. Así, el Ayuntamiento y la Generalitat acuerdan sobre puntos específicos.

En materia de vivienda, el Consorci de l'Habitatge de Barcelona conecta ambas escalas administrativas y les permite intercambiar responsabilidades de planificación urbana (que la ciudad cede a la Generalitat) y de vivienda (que la Generalitat cede al Ayuntamiento de Barcelona). El Consorci es responsable de la planificación en materia de vivienda, del establecimiento de redes entre instituciones públicas, de la promoción de una política de vivienda abordable, de la planificación de acciones de renovación urbana, de la gestión del patrimonio público de viviendas y suelos destinados a la construcción de viviendas sociales, así como de la redacción de reglas y fijación de criterios para la selección de beneficiarios de vivienda social ${ }^{27}$. Gracias al Consorci, la coordinación entre la ciudad y la Generalitat parece no presentar mayores dificultades ${ }^{28}$. Los verdaderos problemas de coordinación se encuentran al seno del Ayuntamiento, debido al complejo reparto de responsabilidades ligadas a la vivienda. Las diferentes prioridades presupuestarias entre departamentos se consideran dentro de las principales causas que dificulta la coordinación de acciones ${ }^{29}$. De igual manera, la distinción entre la dimensión social y económica de la cuestión vivienda se traduce en el reparto de competencias entre los municipios y el Estado (respectivamente), lo que conlleva a una compleja organización entre las diferentes

24 Durante el franquismo, Barcelona y Madrid serán reconocidas a través de decretos que les cederán un régimen (estatuto) particular con el objetivo de mejorar la eficacia en su gestión (Orduña, 2005, p.201). Así, los antecedentes de la Carta Municipal se remontan al mandato de Porcioles (alcalde de Barcelona entre 1957 y 1973), quien introduce nuevas condiciones legales y administrativas para la ciudad con un acento en materia económica. Como dice Busquets, "la Carta da a la ciudad un presupuesto mucho más importante, y apunta a la simplificación de procedimientos financieros y administrativos" (Busquets, 2005, p.330-331).

25 Barceló y Vintró, op.cit., p.516-517

26 Entrevista con Jaume Barnada, en representación del Departamento de vivienda del Ayuntamiento de Barcelona, en el Ayuntamiento de Barcelona, el 01/02/2016.

27 Consorci de l'Habitatge de Barcelona, Funciones, 2016.

28 La principal tarea del Consorci es repartir recursos que llegan desde Estado y la Generalitat. En palabras de Jaume Barnada, “(...) las personas que trabajamos en el Departamento de Vivienda somos las personas del Consorci, y las personas que trabajan en la subsecretaría de la Generalitat, hacen parte del Consorci. Entonces, no hay problema porque somos nosotros mismos." Esta afirmación revela una percepción no conflictiva entre los intereses de la ciudad de Barcelona y de la Generalitat de Cataluña. En todo caso, expresa la idea de que el Consorci es una institución más bien técnica y operacional antes que política. Sin embargo, consideramos necesario matizar tal idea, pues las dos escalas de poder tienen a la cabeza dos partidos políticos diferentes.

29 Entrevista con Jaume Barnada. 
escalas administrativas y en el seno mismo de la ciudad. Esto explica por qué la gestión de la vivienda en el Ayuntamiento de Barcelona está inscrita en el Área de Derechos Sociales, aunque la coordinación con otras áreas (como la de economía) sea constante. Barcelona no posee las competencias económicas para garantizar la producción y la gestión del parque público de viviendas. Este discurso es mantenido por los responsables de la política de vivienda en el Ayuntamiento bajo la siguiente consigna: la vivienda es un derecho social, pero hacerlo vinculante requiere necesariamente garantías económicas que dependen largamente de la escala nacional ${ }^{30}$. A este respecto, la ciudad limita sus acciones a la gestión de situaciones de urgencia; interviene únicamente cuando las unidades de convivencia no pueden satisfacer su derecho a la vivienda vía el mercado (o cuando no pueden responder a la oferta pública por razones de costo u otras).

Los municipios, sin competencias reconocidas en materia de vivienda por la Constitución Nacional, pueden, sin embargo, realizar planes para precisar las orientaciones y programas vinculados al hábitat. Se trata de objetivos amplios y ambiciosos cuya realización no es obligatoria, pero sirven para marcar las principales líneas de acción y orientación política. Para el arquitecto y urbanista Josep M. Vilanova (co-director del Pla Territorial Sectorial de l'Habitatge, publicado el 2010), estos planes plurianuales, generalmente, no se diferencian de la política económica nacional, la cual apunta al crecimiento y al dinamismo económico. Las acciones llevadas a cabo por el Ayuntamiento reposan -evidentemente- en el marco legislativo nacional, el cual favorece la realización de asociaciones público-privadas. Para la ciudad, esto implica una dependencia a las condiciones impuestas por los agentes privados en la realización de operaciones de construcción o en la renovación de viviendas, principalmente en materia de $\operatorname{costos}^{31}$.

Los Planes plurianuales pretenden trascender y resistir el paso de los diferentes mandatos municipales. Sin embargo, esta continuidad (manifiesta también en la permanencia de especialistas técnicos en temas de vivienda a pesar de los cambios de equipos políticos de gobierno) nos interroga sobre la apertura y disposición hacia nuevos enfoques que busquen reformar la política de vivienda al promover otros regímenes de tenencia como la vivienda pública en alquiler, en cesión de uso, la gestión cooperativa, etc. ${ }^{32}$. La promoción de la vivienda en propiedad ha apuntado a atender y orientar la demanda de una clase media, asalariada, y, de este modo, se ha concebido la política municipal de vivienda pública ${ }^{33}$. Hacer una política de vivienda para la clase media implica poner énfasis en el acceso a la vivienda en propiedad o con alquileres elevados, abordables por personas con empleo fijo o, en todo caso, sin dificultad de inserción al mercado laboral. Además, favorece a los agentes financieros-inmobiliarios encargados de producir nuevas viviendas. En el actual

$30 \quad$ Id. Ibid.

$31 \quad$ Vilanova, 1997

32 Alemany et al, 2013

33 Entrevista con Jaume Barnada. Esto está vinculado, evidentemente, a favorecer al capital inmobiliario-financiero, el gran ganador en las operaciones de construcción. 
contexto de emergencia habitacional, donde la mayoría de personas en riesgo de exclusión residencial no cuenta con ingresos fijos ni suficientes para participar en el mercado inmobiliario, la Administración realiza diversas maniobras para conseguir viviendas privadas en alquiler y evitar que las familias no tengan donde pernoctar. Las respuestas estructurales en términos de política económica corresponderían al Estado.

\section{La paulatina flexibilización del mercado de viviendas en alquiler}

\section{Evolución legislativa hostil al inquilino}

Las medidas de congelamiento de los precios de alquiler fueron extensivas durante los primeros años del régimen franquista. Ellas permitieron mantener estables las condiciones de los contratos de alquiler, junto con los mismos precios, durante varios años. Esto se condice con la proporción mayoritaria de familias viviendo en alquiler durante la Guerra Civil (1936-1939), una época de importancia subordinada del capital inmobiliario frente al capital industrial y bancario. Este último es privilegiado a través del control de los gastos de reproducción de la fuerza de trabajo $^{34}$. En 1950, Barcelona registra un 95\% de su población viviendo en régimen de alquiler ${ }^{35}$, pero progresivamente el marco legislativo se torna hostil hacia esta forma habitacional. El régimen franquista se propuso hacer de España un país de pequeños propietarios y utilizó las viviendas como un medio de control social por medio del endeudamiento ${ }^{36}$. La industria de la construcción empieza su apogeo en 1960 $\mathrm{y}$, desde ese momento, se desencadenaron una serie de medidas favorables para el acceso a la vivienda en propiedad y hostiles al alquiler.

Dos cambios serán decisivos para promover el acceso a la propiedad: la promulgación de la Ley de Propiedad Horizontal en 1960 y la Ley de Arrendamientos Urbanos (LAU) en 1964. Ambas expresan la voluntad política por cambiar las condiciones del congelamiento de los alquileres, pues los precios no aumentan considerablemente entre 1920 y 196037. La primera de estas leyes favorecerá la división de los bienes al interior de un mismo edificio ${ }^{38}$ (fenómeno que, como señala la geógrafa Mercè Tatjer, estaba ya en marcha y al cual la medida aporta regularización jurídica) y de esta manera contribuye a la incorporación de muchas viviendas al mercado. La segunda ley apunta a dinamizar el mercado de viviendas en alquiler. La promulgación de la LAU de 1964 modifica las condiciones de arrendamiento, lo que posibilita el aumento de los precios de alquiler. Los contratos firmados después de 1964 muestran un crecimiento considerable de los precios en relación a los contratos firmados antes de la promulgación de la ley (en aquella época, 78\% de las vi-

34 Tatjer, 1988, p.355

$35 \quad$ Naredo, 2010, p.7

36 Rodríguez López, s/f, p. 26-27; Pareja-Estaway y Sánchez Martínez, 2012, p.128

37 Tatjer, op.cit.

38 Ley 49/1960 de Propiedad Horizontal. 
viendas en alquiler suscribieron contratos antes de 1964). La principal consecuencia del congelamiento de los alquileres se revela en términos comparativos, pues los contratos firmados entre 1968-1970 estipulaban un precio cuatro veces más elevado que los contratos firmados antes de 1930 y dos veces más que aquellos firmados entre 1961 y $1964^{39}$. Para decirlo de otra manera, la LAU de 1964 hace más atractivo el mercado de viviendas en alquiler como medio de inversión y favorece la idea de inyectar dinero en la propiedad inmobiliaria. Tanto la LAU de 1964 como la Ley de Propiedad Horizontal señalan la vía de lo que será una progresiva precarización de los inquilinos, lo que se traduce por el alza de los precios de los alquileres y la inestabilidad en relación a la duración de los contratos. Así, la LAU de 1964 aparece menos precarizadora que la Ley 4/2013 de medidas de flexibilización y fomento del mercado del alquiler de viviendas ${ }^{40}$, una de las últimas medidas nacionales relativas a los arrendamientos urbanos.

El alza de los precios de los alquileres ha sido fundamental para incitar a los ciudadanos a satisfacer su derecho a la vivienda al convertirse en propietarios por medio del endeudamiento. Tras la promulgación de la Ley 2/1985 sobre Medidas de Política Económica (Decreto Boyer), el precio de los alquileres aumenta un $80 \%^{41}$. El Decreto Boyer busca dinamizar el sector terciario y la creación de empresas a través de la promoción de la utilización de las viviendas para fines diferentes del habitacional ${ }^{42}$. Conduce entonces a “( ... ) la expulsión de la población popular de las zonas centrales de la ciudad"43. El Decreto Boyer empuja a las familias a endeudarse para acceder a la propiedad al mismo tiempo que precariza las condiciones de los inquilinos suprimiendo la prorrogación forzosa de los contratos (establecidos por la LAU de 1964), creando contratos anuales, sujetos al libre aumento de los precios ${ }^{44}$. En la década de 1990, en pleno contexto de incorporación de España a la OTAN, la especulación inmobiliaria hace del acceso a la vivienda una verdadera pesadilla para las familias. Tras la celebración de los Juegos Olímpicos, aparece en 1994 una

39 M. Tatjer precisa que fue gracias al congelamiento de los alquileres que las familias de ingresos modestos pudieron acceder a la vivienda en pleno contexto de alza de los precios de alquiler (Tatjer, op.cit., p.347-352).

40 Una de las excepciones a esta regla es la cuestión del sub-alquiler, que aparece mejor regulado en la LAU de 1994. Ésta prohíbe el sub-alquiler total de la vivienda y el enriquecimiento a través de esta actividad (Blanco, 2006, p.60-61).

$41 \quad$ Vilallonga, 1991

42 Antes del Decreto Boyer, la transición hacia una economía terciaria es explícita en el Plan General Metropolitano aprobado en 1976, notablemente en lo que compete a la delocalización de industrias obsoletas hacia espacios periféricos y suburbanizados de la metrópoli. Esto permite la descongestión y la reestructuración morfológica de la ciudad-centro a través de grandes operaciones urbanísticas que apuntaban a atraer al sector terciario; los grandes proyectos son vistos como "catalizadores del mercado inmobiliario y del proceso de terciarización de la ciudad" (Tello y Martínez, 1995, p.41-42; Marrero, 2003; Serratosa, 1996, p.14). La designación de Barcelona como ciudad olímpica en 1986 acelera las inversiones y los proyectos apuntan a la creación de espacios apropiados a la celebración de los Juegos Olímpicos de 1992 (Ferrer, 1996: 53 ; Benach y Tello, 2004 : p.101). Como señala Yann Maury (2006, p.69), "Después de 1976, 1986 constituye un segundo momento decisivo con la elección de Barcelona como ciudad olímpica (1992)."

43 Vilallonga, op.cit.

44 Alemany et al, 2013, p.53 
nueva versión de la LAU. Ella pone fin al congelamiento del precio de los alquileres ${ }^{45}$, aunque alarga la extensión de los contratos de 1 a 5 años ${ }^{46}$. La LAU de 1994 prevé la libertad de las partes para pactar las condiciones del contrato, el monto a pagar mensualmente, los gastos por servicios de copropiedad y los gastos por trabajos de renovación de los bienes. La ley hace posible aumentar el alquiler en un 20\% (máximo) en razón de trabajos en el inmueble, pero solamente si el inquilino ha vivido cinco años en él y si tal acuerdo aparece establecido en el contrato ${ }^{47}$. Vemos cómo las medidas legislativas en materia de vivienda apuntan a la financiación de créditos hipotecarios, lo que conduce inevitablemente a la inflación ${ }^{48}$. En 1995, Barcelona es una de las ciudades españolas donde la vivienda es más costosa ${ }^{49}$, y entre 1997 y 2002 , el precio de la vivienda aumenta en $86 \%$, mientras que los salarios progresan solamente en $15 \%{ }^{50}$.

El precio de los alquileres no ha dejado de aumentar. A pesar de las iniciativas del gobierno socialista por promover el régimen de alquiler con la creación de Sociedad Pública de Alquiler en 2005 y con la Renta de Emancipación para los Jóvenes, otras medidas han favorecido, simultáneamente, la agilización de las expulsiones por impago de alquiler o hipotecas ${ }^{51}$. Entre 2000 y 2008, el precio mensual promedio de las viviendas en alquiler se duplica en Barcelona, pasando de $400 €$ a $800 €^{52}$. Numerosas familias no pueden pagar los elevados precios de alquiler (ni a las cuotas de hipotecas) y pierden su vivienda. El informe DESC-PAH señala la dificultad de encontrar información precisa del Consejo General del Poder Judicial, principalmente en lo que concierne a cifras de desalojos realizados o en proceso de realización. Esta institución diferencia, solamente desde el 2013, los desalojos causados por impago de alquiler de aquellos causados por impago de hipotecas. "De hecho, de los 37.545 desalojos contabilizados de enero hasta el mes de junio de 2013, los desahucios por impago de alquiler ascienden a 21.765, prácticamente el doble de los originados en procesos de ejecución hipotecaria" ${ }^{53}$. De otro lado, los propietarios se mantienen muy escépticos y desconfiados para ceder al mercado sus bienes inmobiliarios en una coyuntura donde no tienen la seguridad de que los inquilinos paguen mensualmente. Al mismo tiempo, aguardan que los precios de las viviendas aumenten para obtener mayores ganancias. De esto, resulta un gran número de viviendas vacías y, por el momento, fuera del mercado.

45 Tatjer, op.cit, p.19; Blanco, op.cit., p.62

46 Alemany et al, 2013, p.53

47 Blanco, op.cit., p.98-99

48 Trilla, s/f, p.39

49 Rosa Tello y Sergi Martinez (1995, p. 43-48) muestran que entre 1987 y 1993 , "El precio por metro cuadrado de las viviendas se multiplicó por dos, en ocho de los diez distritos de Barcelona (...)." No obstante, en Nou Barris tal incremento no tuvo lugar, a razón de los problemas estructurales de las viviendas. En 1995, estos autores denunciaron una tendencia a la nivelación de los precios de las viviendas entre las zonas más caras y las más baratas de la ciudad. Las diferencias se reducen debido a que el aumento de los precios es constante en los barrios más baratos. Sin embargo, los distritos más caros aún lo son. Ver también Borja, 2010, p.34.

50 Marrero, 2003.

51 Alemany et al, op.cit., p.53

52 Ajuntament de Barcelona, Contratos y precios registrados de las viviendas de alquiler, 2016.

53 Alemany et al, op.cit., p.12 
Tras la crisis del 2007-2008, se constata, no obstante, un voluntarismo estatal por dinamizar el mercado de los alquileres ${ }^{54}$. Charlotte Vorms, historiadora especialista en producción de las ciudades y mercado inmobiliario, afirma que se trata de un rescate a los promotores inmobiliarios, donde “(...) la refinanciación de su deuda (con una línea presupuestaria especial de 3 millones de euros) implica la cesión a alquiler de las viviendas no vendidas" 55 . En el 2013, se promulga la Ley 4/2013 de medidas de flexibilización y fomento del mercado del alquiler de viviendas, cuyo objetivo es equilibrar el mercado inmobiliario a través de la incorporación del surplus de viviendas vacías al mercado del alquiler. La ley garantiza el derecho a la propiedad inmobiliaria a fin de que los titulares tengan todas las seguridades sobre sus bienes, por ejemplo, frente a casos de impago de alquileres. Esta modifica los procesos relativos a los desahucios y reduce el tiempo del proceso judicial para que las expulsiones se realicen lo más rápido posible ${ }^{56}$. Además, esta ley reduce de cinco a tres años la prórroga obligatoria de los contratos y de tres a uno la prórroga tácita $^{57}$. Incluso, si el contrato ha sido firmado por tres años, nada garantiza al inquilino que podrá quedarse en la vivienda más de un año. Pasados los doce meses, si lo desea, el propietario puede recuperar el inmueble anunciando la decisión al inquilino con dos meses de anticipación ${ }^{58}$. Además, si los alquileres no son registrados en el Ayuntamiento, el contrato puede interrumpirse en caso de que una tercera persona compre la vivienda ${ }^{59}$. Es decir, se incorpora un nuevo motivo de desalojo.

De la reducción del número de años de prórroga obligatoria de los contratos, se desprende también una sobrecarga económica para los inquilinos en relación al coste de los trabajos de mantenimiento y renovación del inmueble. "Dicho de otro modo, el inquilino ha perdido dos años donde no verá aumentar el precio del alquiler" ${ }^{\prime \prime}$. La libre fijación de las condiciones del contrato puede también incluir la actualización anual de los costos relativos a los servicios de mantenimiento de los espacios comunes o privados ${ }^{61}$. La Ley 4/2013 también crea el Registro de sentencias firmes de impagos de rentas de alquiler, donde figuran los datos de inquilinos que han llevado a los propietarios a juicio ${ }^{62}$. El Registro es una base de datos donde converge la información de las personas que, en razón del incumplimiento en el pago del alquiler, han "(...) obligado a los propietarios a recurrir a la justicia para resolver la situación, habiendo dado la justicia razón a los propietarios"63. Es manifiesto el carácter criminalizador y estigmatizante de esta medida hacia las personas que, por

\footnotetext{
54 Véase el Plan Estatal para el fomento del alquiler de viviendas, la rehabilitación edificatoria y la regeneración y renovación urbanas, 2013-2016.

55 Vorms, 2009, p.14

56 Álvarez, 2014, p.750

57 Ley $4 / 2013$, de 4 de junio, de medidas de flexibilización y fomento del mercado del alquiler de viviendas.

$58 \quad$ Pérez Conesa, 2013, p.36

59 Alemany et al, op.cit., p.66

60 Pérez Conesa, op.cit., p.83

61 Id., p.91

62 Ley $4 / 2013$, de 4 de junio, op.cit.

63 Pérez Conesa, op.cit., p.121
} 
diferentes razones, no han podido pagar los alquileres. Otra medida que promueve la Ley 4/2013 es “(...) el recurso a mediación o al arbitraje para que las dos partes puedan resolver sus conflictos" ${ }^{\prime 64}$. Con ello, se pretende evitar los procesos judiciales y reemplazar la justicia pública con la intervención de terceros privados. La ley prevé que el pago a la intermediación sea hecho por las dos partes (inquilino y propietario), y que los conflictos a resolver son relativos a la duración de los contratos, las obligaciones de los inquilinos y propietarios, así como el fin del contrato. Los argumentos a favor de esta vía señalan la lentitud de los procesos judiciales y los “(...) tradicionales problemas ligados al sistema judicial" ${ }^{65}$. Se entiende que es una medida favorable al encogimiento de los servicios públicos de justicia y al desplazamiento de la intervención pública ante conflictos presentes en el mercado inmobiliario.

Sin embargo, el arbitraje no remplaza la determinación judicial para casos relativos a expulsiones. Sobre este punto, la Ley 4/2013 modifica los procedimientos, pues prevé la realización de un proceso monitorio para los casos de impago de alquiler $^{66}$. Esto implica la reducción del tiempo de los procesos judiciales para que las expulsiones se realicen más rápidamente. Así, estas modificaciones relativas a las expulsiones aparecen como una mejora técnica y se alejan de los objetivos iniciales de la reforma ${ }^{67}$. Uno de los problemas que plantea la ley es que no distingue entre grandes y pequeños propietarios para los casos de impago de alquiler. Además, esta norma sería complementaria a la Ley 16/2012 por lo que se adoptan diversas medidas tributarias dirigidas a la consolidación de las finanzas públicas y al impulso de la actividad económica. De este modo, se favorece a los grupos inversores mediante ventajas fiscales, sin importar el uso que den a los inmuebles ${ }^{68}$. La ley 4/2013 busca introducir las viviendas vacías al mercado de los alquileres $y$, de esta manera, contrabalancear la situación que posiciona a España entre los países con menor número de viviendas en alquiler en la Unión Europea ${ }^{69}$. La flexibilización del mercado de viviendas en alquiler criminaliza a los inquilinos y sacrifica su tranquilidad; no se tiene garantías de fijación en la vivienda debido a la inestabilidad residencial que promueve la legislación nacional. Se trata de una medida que busca restaurar la confianza perdida en el mercado de los alquileres y, así, en la compra de bienes inmobiliarios como forma segura de inversión ${ }^{70}$. ¿Es posible perseguir este objetivo y trabajar simultáneamente por un marco normativo favorable al derecho a la vivienda?

\section{$64 \quad$ Id., p.24}

65 Gázquez, 2014, p.559

66 Después de la Ley de Enjuiciamiento Civil del 2000 (que substituye a una vieja ley votada en 1881) se han realizado varias modificaciones. Según Álvarez, “(...) el proceso relativo a las expulsiones ha sido reformado con el objetivo de hacer economía política, y no para mejorar el servicio a los ciudadanos" (Álvarez, 2014, p.722).

67 Álvarez, Id., p.750

68 Alemany et al, op.cit., p.66

69 Como lo muestra García, según los datos del último censo nacional, en el 2011, España cuenta con 25208623 viviendas (20.3\% más que en 2001), de las cuales 3443365 están vacías (13.65\% del parque total) (García, 2014, p.682; ver también Rodríguez López, s/f, p.26).

70 López y Rodríguez, 2010, p.219 


\section{El abandono de los inquilinos al impredecible comportamiento del mercado inmobiliario}

Los cambios evocados demuestran la responsabilidad de la legislación nacional en la precarización de las condiciones de acceso y mantenimiento en la vivienda de alquiler ${ }^{71}$. La inestable situación que resulta para los inquilinos no favorece la inversión personal ni material en la vivienda, pues nada garantiza las condiciones para enraizar ${ }^{72}$. Esta situación de precarización conducirá a la reducción de los precios de los alquileres y, al mismo tiempo, no motivará la inversión de los propietarios -ni de los inquilinos- en el mantenimiento de la vivienda. Por el contrario, hay quienes opinan que la excesiva oferta de viviendas no implica una disminución del costo de los alquileres; además, esta favorece la imposición de condiciones abusivas de parte de los propietarios ${ }^{73}$.

En relación a los precios de los alquileres y de la compra-venta de viviendas, no hay consenso sobre el comportamiento del mercado inmobiliario. Para el reconocido economista José Manuel Naredo, cuando las viviendas se valorizan y la oferta es elevada, las personas eligen comprar y, enseguida, los precios del alquiler bajan. Al contrario, cuando los precios de compra aumentan, los precios de los alquileres también suben. Por otro lado, si la demanda de viviendas en alquiler a bajo precio aumenta, la saturación del mercado (debido al insuficiente parque habitacional ofertado para cubrir la necesidad de viviendas asequibles) puede conducir a un aumento de los precios ${ }^{74}$. De su parte, Beatriu Guarro afirma que después de la crisis “(...) los precios de compra [de viviendas] no han disminuido de manera excesiva y, al contrario, los precios de alquiler han aumentado"75. Según la autora, quien ha trabajado sobre dificultades en el acceso a la vivienda para las personas inmigradas $^{76}$, esto se explica por las numerosas facilidades dadas para acceder a créditos

$71 \quad$ Herrera, op.cit.

72 Pérez, 2013, p.33

73 Ruipérez, 2014, p.177

$74 \quad$ Naredo, 2010

75 Guarro, 2012, p.54

76 En España, observamos un aumento del número de extranjeros desde 1980. Entre 1981 y 1994, el número de extranjeros pasó de 0.5\% de la población total del país al 1.5\% (Capel, 1997). Ramón Díaz y sus coautores constatan un "vertiginoso crecimiento de flujos migratorios internacionales" hacia las principales ciudades españolas, sobretodo en dirección a Madrid y Barcelona (Díaz et al, 2010). En Barcelona, del total de población extranjera el año 2000 (58 186 personas), la mayoría vienen de América del Sur (32.4\%) y, de este grupo, la mayoría son mujeres (57.6\%) (Marre, 2001). Algunos trabajos dan cuenta de los efectos de la inmigración en el mercado inmobiliario, como el alza de los precios y la saturación de la oferta de vivienda barata, lo que afectaría principalmente a los barrios populares mediante el incremento de la competencia. Algaba (2003) señala que para acceder a la vivienda, las personas inmigrantes deben aceptar ciertas condiciones como pagos más altos que los nativos (debido a su urgente necesidad, la menor información y la discriminación de la que suelen ser objeto) y vivir en condiciones de hacinamiento, frecuentemente en sobreocupación. Sobre este último punto coinciden otros autores como Horacio Capel (2001), quien explica que la sobreocupación se debe a "(...) los precios abusivos, el estricto plan de ahorro de los inmigrantes y su solidaridad intragrupo". La cuestión de la solidaridad entre los inmigrantes es trabajada por Eduardo Riol (2003) en un interesante estudio sobre el colectivo pakistaní en Barcelona. E. Riol considera que la solidaridad en este grupo responde a cuestiones culturales (la "cultura musulmana pakistaní") y familiares (ligadas a los proyectos de reagrupación). 
hipotecarios, mientras ninguna medida ha buscado asegurar el mercado de viviendas en alquiler.

El debate en torno al comportamiento de los precios está lejos de cerrarse. Es preciso tener en cuenta que entre las personas que compraron viviendas por medio de créditos hipotecarios también hay inversores (tanto pequeños propietarios como grandes tenedore ${ }^{77}$ ) a la espera de que aumenten los precios, pues esperan vender o alquilar sus bienes a un precio que convenga a sus expectativas ${ }^{78}$. Carme Trilla, antigua responsable de la Secretaría de Vivienda en la Generalitat de Cataluña, suscribe este argumento y afirma que los propietarios de viviendas han invertido en el sector inmobiliario a la espera de sacar ganancias con el alquiler. Entonces, mientras más altos fueron los precios de las viviendas que compraron, más esperan ganar en alquileres $^{79}$. Ella considera que la evolución del precio del mercado del alquiler sigue la tendencia de los precios de venta y, en consecuencia, “(...) no es posible considerar que, en medio de un importante proceso inflacionista como una burbuja, la inflación de los precios de compra no va a transferirse hacia los precios del alquiler. En un contexto con dichas características, es un error de concepto plantear el alquiler de mercado como la solución para hacer frente a los precios elevados de compra"80.

Ciertamente, en Cataluña el precio de compra de viviendas nuevas y de segunda mano ha disminuido de manera constante desde 2007 y, después del 2013, la evolución muestra una estabilización. Sin embargo, a partir del primer trimestre de 2015 , los precios comenzaron a aumentar nuevamente ${ }^{81}$. De igual manera, la evolución del precio medio de vivienda en alquiler en Barcelona muestra que entre 2000 y 2008 se ha multiplicado por dos, antes de decrecer ligeramente después de 2008. Pero, entre 2014 y 2015, se observa un aumento. Los precios de viviendas en alquiler en la ciudad oscilan alrededor de $700 €$ al mes ${ }^{82}$.

Según nuestro trabajo de campo, pudimos constatar la situación de estrés que se vive en el mercado del alquiler a causa del reducido número de viviendas ofertadas. Además de la dificultad que representa el pago, otro gran problema de las familias es la dificultad para satisfacer todos los requisitos de las agencias inmobiliarias. En razón de la libertad para fijar las condiciones entre los propietarios y los inquilinos, los poderes públicos no regulan los criterios demandados por las agencias inmobiliarias o los Administradores de Fincas, tradicionales aliados de los pequeños propietarios y garantes del derecho a la propiedad en Barcelona. Ellos están a cargo del control del acceso a la vivienda en alquiler y de todas las tareas relativas a la gestión de inmuebles: colecta de alquiler, seguimiento a los inquilinos, etc. ${ }^{83}$ Hemos visitado las

$77 \quad$ La expresión "grandes tenedores" es común en el medio activista y en la gestión pública local. El término hace referencia a los inversionistas bancarios-financieros propietarios de varios inmuebles.

78 Rodríguez López, s/f, p.27-28

79 Trilla, s/f

$80 \quad$ Trilla, op.cit., p.39

$81 \quad$ Instituto Nacional de Estadística, 2015.

82 Ajuntament de Barcelona, Contratos y precios registrados de las viviendas de alquiler, 2016.

83 Mercè Tatjer documenta, para el caso del barrio de La Barceloneta, que los Administradores de Fincas tenían el control del 75\% del mercado de los alquileres y también del mercado de compra-venta de inmuebles (Tatjer, 1988, p.360). Además, ella cuenta que ellos estaban especializados 
agencias inmobiliarias presentes en el distrito de Nou Barris y todas manifestaron el bajo número de viviendas que ingresan para ser ofertadas en alquiler desde fines de 2015. La oferta disponible es muy reducida y no garantiza la posibilidad de permanecer más de un año. Proponen tomar los datos del cliente, así como las características del producto buscado, y prometen llamar ante la aparición de una vivienda que corresponda a nuestra búsqueda.

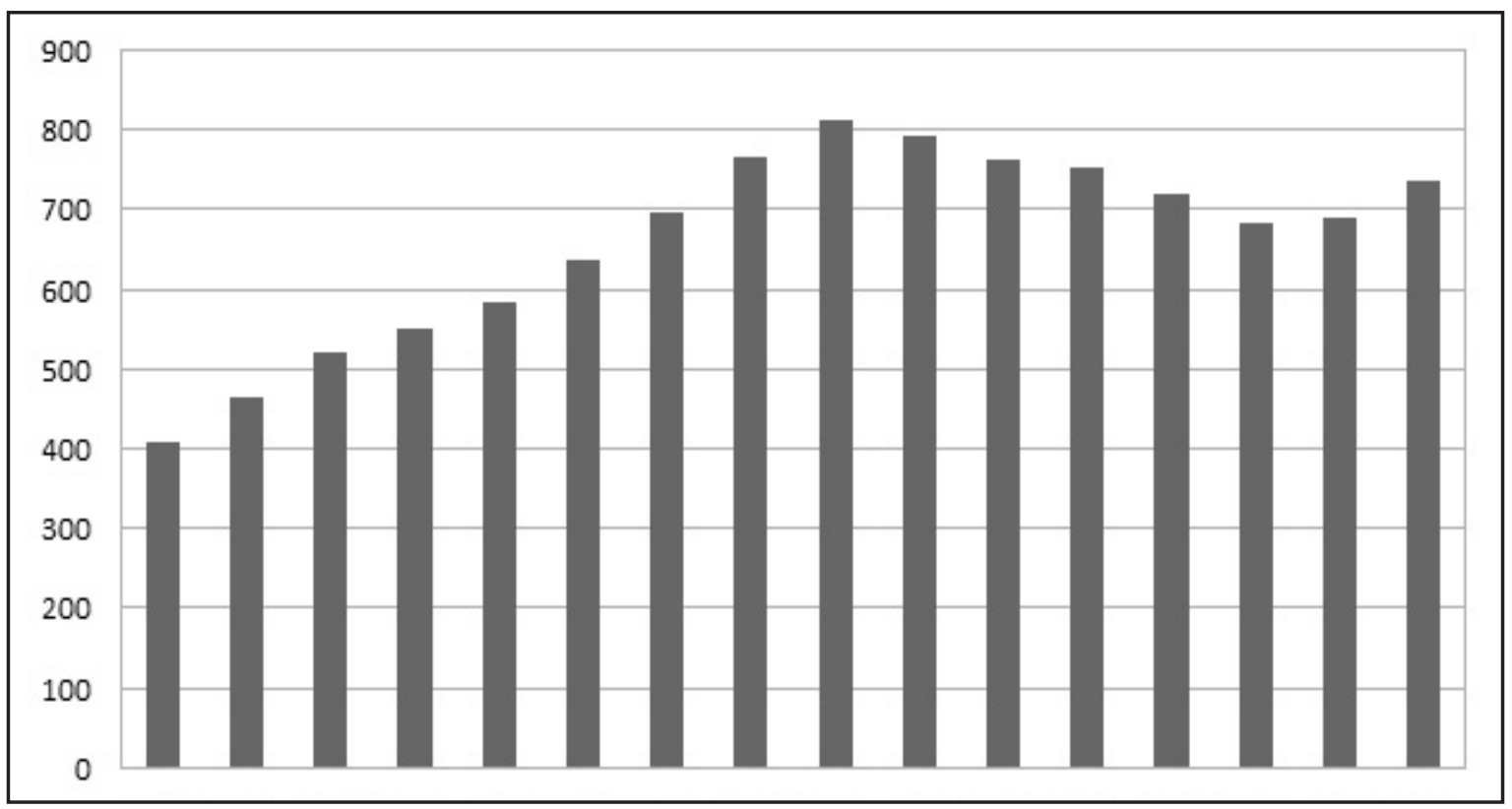

Figura 1. Evolución del precio mensual de viviendas en alquiler, Barcelona, 2000 -2015. Elaboración propia. Fuente: Ayuntamiento de Barcelona.

El estrés y la incertidumbre que resultan de la falta de viviendas ofertadas explica también el endurecimiento de los criterios demandados. En relación a los precios, éstos oscilan entre $450 €$ y $800 €$ según el número de piezas, ubicación del inmueble, disponibilidad de ascensor en el edificio, etc. El precio determina también el costo total a pagar por la obtención de un contrato. Todas las agencias demandan un adelanto de alquiler por el mes corriente, dos meses de garantía (o más) y el equivalente a un mes de alquiler por los costos de agencia. Esto implica disponer de cuatro meses de alquiler a adelantar para acceder a una vivienda (alrededor de 3000€ para personas buscando una vivienda con dos habitaciones). Pero esto no es novedad, pues, desde inicio de 1990, las agencias inmobiliarias demandan varios meses de garantía, además de un aval personal y/o bancario (lo que implicaba el pago mensual de intereses a la entidad financiera $)^{84}$. Además, los criterios requeridos no se limitan a la disponibilidad de dinero y ello complica enormemente la situación de las familias. La firma del contrato está condicionada a la presentación de las tres últimas boletas de pago y el contrato de trabajo de las personas que firmarán. Las exigencias sobre el contrato de trabajo varían de una agencia a otra: algunas solicitan contratos de

territorialmente. Ciertas empresas tenían el monopolio en algunos barrios.

84 Ruipérez, 2014, p.46 
duración indeterminada, otras demandan contratos de por lo menos un año (tiempo de duración del contrato de alquiler). En todos los casos, el monto del alquiler debe ser igual o menor a 30\% de los ingresos mensuales en base a la suma de ingresos de la unidad de convivencia. Sobre el número de personas que aparecerán en el contrato, algunas agencias autorizan la aparición de dos o más personas, pero esto deberá ser validado por los propietarios. La evaluación de las candidaturas está condicionada a varios criterios. Además, algunas agencias demandan seguros de pago, un dispositivo de evaluación de los contratos de trabajo que juzga la elegibilidad de los candidatos en función al tipo de contrato laboral. El éxito de la evaluación depende de la estabilidad de los ingresos.

Sin embargo, la idea de regular el mercado del alquiler, por ejemplo, a través de la fijación de precios de alquiler no es extraña a la actual gestión. El Departamento de Vivienda del Ayuntamiento de Barcelona baraja la idea de fijar precios referenciales de alquiler para cada barrio de la ciudad, pero en ningún caso tal medida sería de obligatorio cumplimiento por parte de las agencias ${ }^{85}$. La no intervención pública en el mercado de alquiler de viviendas, notablemente en lo que respecta a las condiciones de acceso, indica un comportamiento hostil hacia las personas en búsqueda de vivienda, principalmente hacia las unidades de convivencia con ingresos modestos que no cuentan con empleo fijo ni con contratos que satisfagan las condiciones de los propietarios. En un contexto de precarización del inquilino, las familias despliegan diversas estrategias para acceder o mantenerse en la vivienda. En la mayoría de los casos, deben paliar la inexistencia de un contrato de trabajo ${ }^{86}$.

\section{La gestión local de la propiedad pública de viviendas en el contexto de emergencia habitacional}

\section{Una pobre oferta de vivienda social}

La Obra Sindical del Hogar (1942-1975) fue uno de los mayores constructores de vivienda social durante el franquismo ${ }^{87}$. Con la transición a la democracia en 1976, el Estado reduce paulatinamente su parque público de viviendas, al mismo tiempo que se priorizan inversiones públicas en la construcción de infraestructura colectiva $^{88}$. La no responsabilización del Estado como prestador del servicio de vivienda implica la progresiva privatización de las viviendas sociales a lo largo de 1980, cuando España se alinea muy activamente en el Espacio Económico Europeo, lo que atrajo un importante flujo de capitales hacia las principales ciudades españolas ${ }^{89}$. Los habitantes de las viviendas de la Obra Sindical del Hogar se descubren propietarios de departamentos de muy mala calidad sin una institución pública responsable

85 Entrevista con Jaume Barnada, op.cit.

86 Herrera, 2016

87 Tatjer, s/f, p.17; 2005

88 Naredo, 2010; Tello y Martínez, 1995; Benach y Tello, 2004

89 Tello, 2012 
de gestionar la situación ${ }^{90}$. El patrimonio de viviendas públicas fue transferido en 1985 a la Generalitat de Cataluña y la empresa pública de Administración y Gestión (ADIGSA) será la entidad encargada de renovar la herencia inmobiliaria ${ }^{91}$. Al momento de realizarse la transferencia, las viviendas presentaban importantes problemas estructurales, lo que fue causa de movimientos sociales urbanos para que los poderes públicos tomaran cartas en el asunto ${ }^{92}$.

El Ayuntamiento de Barcelona también jugó un papel en la producción de vivienda social. En 1927 se crea el Patronato Municipal de Vivienda de Barcelona (PMHB) que construye las "casas baratas", el primer ejemplo de vivienda social en España ${ }^{93}$. Esta institución construye varios polígonos en las periferias de la ciudad, donde serán enviados los “( ...) grupos populares y obreros, o aquellos que representaban problemas sociales (ciertos grupos de barracas)" ${ }^{\prime \prime 9}$. Tras la muerte de Franco, la Constitución de 1978 establece las competencias para las diferentes escalas administrativas y la cesión de responsabilidades en materia de vivienda a las comunidades autónomas se realiza en el mismo momento en que el Estado se desembaraza económicamente del tema. En España, son básicamente los ayuntamientos y las comunidades autónomas quienes poseen el mayor número de viviendas públicas, pero este patrimonio sólo representa el $1.5 \%$ del total del parque de viviendas ocupadas ${ }^{95}$. Para el caso de Cataluña, el intercambio de competencias con Barcelona en materia de vivienda y urbanismo implica también la mutualización de responsabilidades para la búsqueda de recursos financieros a fin de enfrentar la necesidad de vivienda social. El financiamiento de la construcción o de la compra de viviendas públicas no está garantizado por el Estado ${ }^{96}$.

La regulación de la oferta de viviendas fue dejada en manos del mercado y la ciudad se encuentra con escasos medios financieros y jurídicos para gestionar su desarrollo inmobiliario. La década de 1980 implica un ascenso de las ideas neoliberales traducidas en la gestión de la ciudad, notablemente por medio de la colaboración público-privada ${ }^{97}$. La acción pública empresarial busca movilizar el financiamiento

$90 \quad$ Mercè Tatjer explica también que una de las modalidades más frecuentes para acceder a la propiedad era el acceso diferido, que consistía en pagos mensuales (a manera de alquileres) acumulativos que a la larga conducían a la propiedad del hogar. El resultado (luego de diez, quince o veinte años) era la reducción del patrimonio público de viviendas y el consecuente incremento del parque privado. Como señala Rosa Tello, varias familias de pronto se encontraron propietarias de bienes en malas condiciones y debieron asumir varias responsabilidades en tanto que propietarios, notablemente en cuanto al mantenimiento de los espacios comunes, pero también en cuanto a los trabajos de renovación. Entrevista con Rosa Tello (07/12/15) y con Mercè Tatjer (11/12/15), en la Universidad de Barcelona. Ver también Equip EARHA, 2003.

$91 \quad$ Tatjer, 1995a; 1995b

92 Tatjer, 1995a; 1995b; Fabre y Huertas, 1997

93 Busquets, 2005, p.290

94 Tatjer, s/f, p.20

95 Entrevista con Jaume Barnada, op.cit. En el 2004, 82.2\% de las familias españolas habitaba en una vivienda de propiedad, $1 \%$ habitaba en vivienda pública de alquiler, y $10 \%$ en el mercado privado de alquiler (Maury, 2006). Cifras más actuales muestran que, a la escala de Barcelona, el parque público representa sólo 1.5\% del total (datos presentados en el preámbulo de la Ley 24/2015).

96 Rodríguez López, op.cit., p.35

97 Capel, 2010, p.179 
a través de la generalización de este tipo de colaboraciones, donde son las ciudades las que asumen largamente los riesgos asociados a los proyectos ${ }^{98}$. Varios actores participan, entonces, en las operaciones de producción de viviendas sociales en Barcelona: el Instituto Catalán del Suelo (INCASOL), sindicatos como la Unión General de Trabajadores (UGT) y las Comisiones Obreras (CCOO), cooperativas, la Federación de Asociaciones de Vecinas y Vecinos de Barcelona (FAVB), además de fundaciones y promotores privados ${ }^{99}$. Como lo remarca Yann Maury en un estudio encargado por el Ministerio de Vivienda francés, la mayoría de estas operaciones están destinadas a la venta y no al alquiler, lo que restringe el acceso a las familias que no cuentan con los medios para suscribir créditos hipotecarios. Sin embargo, existen instrumentos de seguimiento a las políticas de vivienda que agrupa a diversos agentes sociales de la ciudad. Es el caso del Consell de l'Habitatge Social de Barcelona (incorporado al Consorci), cuyo carácter consultivo y de participación busca asegurar el adecuado funcionamiento del Registro de solicitantes de vivienda protegida y la atención a personas en riesgo de exclusión residencial ${ }^{100}$.

Actualmente, hay 10.522 viviendas protegidas ( $\mathrm{VPO}^{101}$ ) en Barcelona, de las cuales la mayor parte es gestionada por el Patronato Municipal de la Vivienda de Barcelona- PMHB (6.111 viviendas, que representa el 58.08\% de VPO en la ciudad ${ }^{102}$. La vivienda protegida en España se atribuye en función a los ingresos económicos de las unidades de convivencia que son ponderados según el Indicador Público de Renta de Efectos Múltiples- IPREM ${ }^{103}$. Así, existen tres grandes categorías de viviendas públicas y cada una posee diferentes regímenes de acceso: vivienda concertada (en venta, para ingresos inferiores a 6.5 veces el IPREM: 3461.32 $€^{104}$ ), la vivienda protegida (en venta, alquiler y derecho de superficie, para ingresos mensuales entre 2.5 y 4.5 veces el IPREM: $1331.2 €-2396.3 €)$, y la vivienda a título provisional o dotacional (en alquiler, para ingresos mensuales inferiores a 1331.2€). Concentraremos la exposición en este último tipo de viviendas. Hasta la fecha, el Plan de Vivienda de Barcelona para el período 2008-2016 es el último documento de planificación de la política de vivienda local. El Plan estipula que las unidades de convivencia con ingresos inferiores a 2.5 veces el IPREM (1331.27€) pueden acceder a cinco tipos de vivienda, según los ingresos y las situaciones de vulnerabilidad social. La Mesa de Valoración para la atribución de vivienda en caso de urgencia social (en adelante

\footnotetext{
$98 \quad$ Harvey, 1989

99 Maury, 2006, p.74

100 Consorci de l'Habitatge de Barcelona, Consell de l'Habitatge Social de Barcelona, s/f.

101 Vivienda de protección oficial, vivienda social o hábitat de protección serán usados como sinónimos (Maury, op.cit.; Arends, 2012).

102 Datos del Consorci de l'Habitatge de Barcelona, Sessió Plenària 19/01/2016. En 2003, Maury constata un parque de 3380 viviendas pertenecientes al PMHB (Maury, op.cit., p.74-75). Esto quiere decir que el parque público de viviendas ha aumentado.

103 El IPREM toma en cuenta las características de la unidad de convivencia (número de personas) y la suma total del ingreso mensual.

104 En 2004, el IPREM mensual era de $460.50 €$ y desde el 2010 está estipulado en 532.51€. Hemos calculado utilizando el IPREM del 2014 (532.51€ mensual). Sin embargo, en el Plan de Vivienda de Barcelona 2008-2016, el IPREM se calcula en 516.90€ al mes.
} 
Mesa de Emergencia) es la entidad responsable de la evaluación de las candidaturas y decide qué solución proponer a las familias en riesgo de exclusión social. No siempre hay posibilidad de ofrecer una vivienda. El Plan prevé para esos casos que las familias con un ingreso mensual inferior a 2 veces el IPREM (1065.02€) y que se encuentren en situación de vulnerabilidad social y económica (expulsión de la vivienda, catástrofes, etc.) pueden acceder a ayudas provenientes de un Fondo de Alquiler Social. En este caso, es el Ayuntamiento quien debe buscar una vivienda en el mercado de alquiler y, según el acuerdo al que se llegue con el propietario, proponérsela a la familia solicitante y subvencionar una parte del alquiler ${ }^{105}$.

Ante la dificultad que presenta acceder a la vivienda para las personas que no satisfacen las condiciones demandadas en el mercado del alquiler, el Ayuntamiento se responsabiliza de este paso por medio de la realización directa de los convenios con los propietarios. Es el Ayuntamiento quien garantiza a los arrendadores el buen estado del inmueble una vez finalizado el contrato. También, se responsabiliza del pago del alquiler y realiza los depósitos directamente a la cuenta de los propietarios $^{106}$. Tras la crisis de 2007-2008, las promociones públicas destinadas a la venta han tenido problemas para suscribir contratos con personas interesadas debido a la reducción del otorgamiento de créditos hipotecarios por parte de instituciones bancarias ${ }^{107}$. De acuerdo a nuestras entrevistas, este rechazo de viviendas públicas en venta -e incluso en alquiler- se explica también por el hecho de que las personas no se sienten convencidas de la ubicación de los inmuebles ofrecidos por el Ayuntamiento. Como realizan un esfuerzo importante para el pago, prefieren encontrar una vivienda que les satisfaga totalmente. El barrio es un criterio decisivo para aceptar la oferta púbica y aquellos barrios estigmatizados son evitados debido al temor que tienen las familias a sufrir actos de violencia, además de marginalización. Comprendemos cómo la Administración debe enfrentar varios desafíos. Por un lado, satisfacer la necesidad en vivienda, renovar y mantener en buen estado el parque público de vivienda y, además, debe buscar financiamiento para las operaciones, sin discriminar barrios beneficiarios de las inversiones.

Del total de parque público disponible hasta fines de 2015 ( 10.522 viviendas $\left.{ }^{108}\right)$, $23.72 \%$ se ha destinado para alquilarlo a las unidades de convivencia en riesgo de exclusión residencial. Además, 140 viviendas han sido añadidas por entidades

105 Se considera que el monto a pagar mensualmente por el alquiler de una vivienda no debe superar el 30\% de los ingresos de la unidad de convivencia. Cuando una familia se encuentra en riesgo de exclusión residencial y el $30 \%$ de sus ingresos (supongamos que el total de ingresos es $800 €(100 \%)$ y el $30 \%$ representa $240 €)$ no alcanza para cubrir el costo de un alquiler, el Ayuntamiento de Barcelona puede aporta esa diferencia, previa inscripción de la unidad de convivencia en el Registro de Solicitantes.

106 Es el caso con el "Programa Pisos Buits", o con otros incentivos que buscan pisos que el Ayuntamiento pueda alquilar -o previamente rehabilitar- para darlos en alquiler. Fuente: Sitio web del Consorci de l'Habitatge de Barcelona; entrevista con Jaume Barnada, op.cit.

107 Rodríguez López, s/f

108 El Plan de Vivienda de Barcelona para el período 2008-2016 prevé la construcción de 18000 viviendas nuevas, de las cuales 400-500 estarían destinadas a alquiler social (Barnada y Fajarí, 2009, p.73). 
privadas ( 118 obtenidas por Hábitat 3 para situaciones de urgencia social, y 22 por entidades financieras $)^{109}$. La vía de las ayudas monetarias para situaciones de exclusión residencial se explica por una oferta de mercado difícilmente abordable por las familias. En 2003, Yann Maury calcula que 25\% de la población está excluida del acceso a la vivienda en Barcelona ${ }^{110} \mathrm{y}$ actualmente este porcentaje asciende a $30 \%{ }^{111}$. El acceso al parque público de viviendas responde a una cuestión de cálculo y azar, pues la demanda de vivienda pública sobrepasa largamente la oferta que brinda la Administración.

\section{La Oficina de Vivienda y la contención de las demandas de vivienda pública}

El Consorcio de Vivienda de Barcelona está a cargo de la gestión de la política de vivienda en la ciudad. La red de Oficinas de Vivienda está presente en cada distrito y en sus instalaciones se realizan las demandas de vivienda social, como también otros trámites relativos al mantenimiento en la vivienda (pedido de ayudas monetarias para el pago de los alquileres, por ejemplo $)^{112}$. La paulatina privatización de las viviendas sociales explica el reducido número de viviendas en el parque público, lo que hoy no permite atender la demanda de la población, principalmente de quienes no cuentan con los ingresos suficientes para satisfacer las exigencias del mercado o de las promociones públicas (para venta o alquiler). El parque público se ha reducido a tal punto que la crisis del 2007-2008 revela a España entre los países europeos con el menor número de viviendas protegidas por el Estado ${ }^{113}$. A fin de administrar adecuadamente la baja disponibilidad de vivienda pública, el Estado exige a las comunidades autónomas y a los ayuntamientos la creación de un Registro de Solicitantes de Vivienda Protegida. La información sobre el número de personas demandantes de vivienda social debería permitir al Ayuntamiento asumir responsabilidades y planificar el aumento de su parque público de viviendas. En Barcelona, el Registro de Solicitantes fue creado el 2008 y concentra información sobre procedimientos administrativos iniciados por los habitantes que desean acceder a la vivienda pública. Sin embargo, el Registro está desbordado, como también lo están las Oficinas de Vivienda. Son especialmente los jóvenes adultos (entre 18 y 35 años) quienes se inscriben esperando acceder a una vivienda abordable ${ }^{114}$. En 2010, había 26.465 unidades de convivencia inscritas en Barcelona, para una oferta de 12.519 residencias bajo diferentes regímenes ${ }^{115}$. En 2015, se reportan 28.238 inscritos en la ciudad $^{116}$.

109 Datos del Consorci de Habitatge de Barcelona, Sessió Plenària, 19/01/2016.

110 Maury, op.cit., p.72

111 Entrevista con Jaume Barnada.

112 Desde el 2015, hay un programa de ayuda al pago de facturas de electricidad y agua, así como de servicios de consulta jurídica.

113 Tello, 2012, p.17; Guarro, 2012, p.57. Hay tres viviendas sociales en España por cada 1000 habitantes, lo que la sitúa muy por debajo de Italia (16), Alemania (30), Francia (48), Gran Bretaña (71) y Holanda (179) (Maury, op.cit., p.11).

114 El precio de las viviendas protegidas es en promedio $21 \%$ inferior al precio del mercado (Oller, s/f, p.124).

115 Id., p.117

116 Datos del Consorci de l'Habitatge de Barcelona, Sessió Plenària, 19/01/2016. 
Para el caso del distrito de Nou Barris, la mitad de las personas inscritas tienen ingresos mensuales entre $213 €^{117}$ y $798.75 €$, mientras que el $19 \%$ no tiene ingreso alguno o posee un ingreso mensual inferior a $213 €^{118}$. En relación al número de personas que componen la unidad de convivencia inscrita, es muy interesante notar que la mayoría de inscritos viven solos (53\% en Barcelona y 45\% en Nou Barris). A pesar de ello, las cifras de inscritos continúan siendo muy bajas en el distrito de Nou Barris: al 30 de junio de 2014, sólo un 4.78\% de la población se encuentra inscrita en el Registro. Esta cifra supera al promedio en Barcelona (3.34\%), pero está por debajo de Ciutat Vella, que es el distrito con mayor número de inscritos en relación a su población total $(6.14 \%)^{119}$. Las formas de atribución de las viviendas (por cálculo y sorteo) dicen mucho sobre la reducida oferta pública. Entre 2009 y 2015 se realizaron un total de 47 procesos de atribución de vivienda en Barcelona, donde participaron 85.545 personas para la atribución de 4.327 viviendas ( $22 \%$ vía cálculo y $88 \%$ vía sorteo). Es decir, del total de participantes, sólo 5\% tuvo una vivienda social ${ }^{120}$. La incertidumbre de la atribución lleva a los inscritos a probar otras opciones propuestas por el Consorci, como las ayudas monetarias para el pago de los alquileres. La supresión de subvenciones estatales para la construcción de vivienda se acopla con el fomento de ayudas monetarias hacia familias a fin que ellas puedan acceder al mercado del alquiler (o pagar sus créditos hipotecarios). De esta manera, el déficit de vivienda de propiedad pública es compensado con la promoción del mercado de viviendas en alquiler.

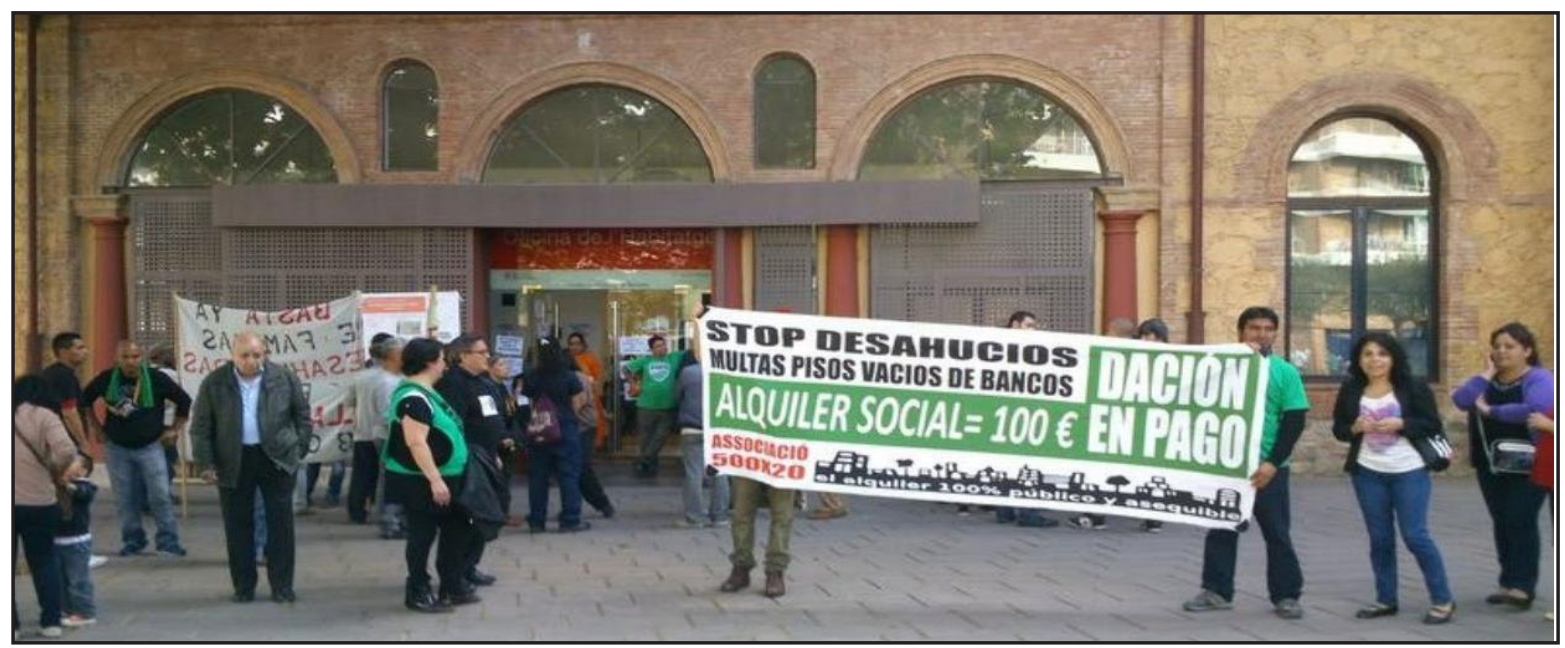

Figura 2. Manifestación frente a la Oficina de l'Habitatge - distrito de Nou Barris.

Fuente: Asociación 500x20 y Prou Especulació!, 05/09/2013.

De acuerdo con las entrevistas realizadas, los inscritos comparten la percepción de que la vivienda social es menos cara que el precio del mercado y ello representa su principal ventaja. Asimismo, acceder a la vivienda social permitiría permanecer

117 Ingresos calculados con el IPREM mensual del 2014: 532.51€.

118 Los porcentajes son similares a la escala de Barcelona. Fuente: Consorci de l'Habitatge de Barcelona, Informe de situació al 31/12/2015 de Barcelona y districte de Nou Barris, 2016.

119 Consorci de l'Habitatge de Barcelona, Sessió Plenària, 19/01/2016, p. 25.

120 Id.Ibid. 
más tiempo con menos incertidumbres relativas al término de los contratos. Sin embargo, incluso si el proceso de inscripción en el Registro no es percibido como difícil, demanda mucho tiempo para resultados totalmente inciertos. Registrarse no implica la entrega inmediata de una vivienda y los demandantes se encuentran frente a la necesidad de buscar otras maneras de acceder a una vivienda asequible. La experiencia de espera se acompaña junto con un sentimiento de frustración y un recuerdo de pérdida del tiempo por cada vez que hizo falta ir a la Oficina de Vivienda a llevar algún documento o realizar alguna consulta. Además, dichos documentos tienen una fecha de caducidad que obliga a los solicitantes a revalidarlos permanentemente y hacer el trámite en las instituciones públicas respectivas.

La manera en que funciona la atribución de vivienda social no está clara para los inscritos. Los entrevistados manifiestan que se prioriza a las personas que se encuentran en situación de urgencia o a las familias con menores de edad antes que a las personas de la tercera edad o quienes viven solas. Se percibe también que los solicitantes deben hacer un espectáculo (llevar a todos sus hijos a la Oficina de Vivienda o llorar frente al personal) para conseguir la atribución ${ }^{121}$. Así, una situación dual se presenta: se debe aceptar la oferta pública al momento de una atribución (incluso si el precio es muy elevado y no se diferencia demasiado de los precios de mercado $^{122}$ ), o es indispensable estar en una situación realmente crítica para que los responsables puedan movilizar los recursos necesarios y evitar que una familia se quede en la calle ${ }^{123}$. Las familias que se encuentran en una situación intermedia deben esperar o buscar otras alternativas en el mercado. El carácter técnico del Registro y el hecho de que los responsables administrativos no posean -aparentemente- margen de maniobra para garantizar la atribución de viviendas despolitiza la situación del ínfimo número de viviendas públicas disponibles para el alquiler y eclipsa este problema bajo el argumento de la lentitud de la atribución o el inconcluso proceso de inscripción por parte de los interesados. Como lo constatamos durante nuestras entrevistas y observaciones, el personal de la Oficina de Vivienda está sobrecargado de trabajo y necesitan aumentar el número de empleados, pero el Ayuntamiento tiene prohibido contratar personal y otras alternativas son evaluadas para reforzar el servicio ${ }^{124}$.

Con la crisis y la imposibilidad de resolver el problema de vivienda a través de la atribución de vivienda social, en el 2009, se crea el anteriormente mencionado Fondo de alquiler social ${ }^{125}$. Para beneficiarse de este fondo, es preciso inscribirse

121 Entrevista 1, mujer inscrita en el Registro, Oficina de Habitatge de Nou Barris, el 04/12/2015 122 Es el caso del programa "Bolsa de Alquiler", donde el Ayuntamiento pide a los propietarios ceder sus viviendas vacías a precios sociales, a cambio de trabajos de renovación.

123 Según un estudio llevado a cabo por el Ayuntamiento de Barcelona entre el 18 y el 19 de mayo de 2016, hay 941 personas que duermen en la calle en la ciudad, mientras que 1973 se encuentran en equipamientos sociales a la espera de una alternativa durable de vivienda. Fuente: Ajuntament de Barcelonal, Més de nou-centes persones dormen al carrer a Barcelona, el 19/05/2016.

124 Entrevista con Jaume Barnada y Carolina Recios, elegida conseiller (partido Barcelona en Comú) en el distrito de Nou Barris, a cargo del seguimiento a los Servicios Sociales, el 25/01/2016.

125 Sitio web del Consorci de l'Habitatge de Barcelona. 
al Registro. Para ello, se presentan varios documentos otorgados por los Servicios Sociales. Ésta institución es decisiva en el acceso a la vivienda en Barcelona, pues son las asistentas sociales quienes siguen los casos de las personas en situación de vulnerabilidad social y riesgo de exclusión residencial. Corresponde a las asistentas sociales validar la situación de precariedad en la cual se encuentran las familias sin ingresos o con bajos ingresos y que desean realizar su inscripción al Registro. La dispersión de las soluciones en materia de vivienda se traduce en constantes idas y vueltas entre la Oficina de Vivienda y los Servicios Sociales. Es el caso con los documentos demandados para acceder al Fondo de alquiler Social como los justificativos de ayudas sociales para los niños o las piezas justificativas de violencia familiar.

Como lo expresa la socióloga Carolina Recios, todo ha caído sobre los Servicios Sociales ${ }^{126}$. La crisis encontró un modelo de servicios sociales no universal y asistencialista, que criminaliza la pobreza y desconfía de las personas en situación de precariedad. Además, al igual que la Oficina de Vivienda, los Servicios Sociales requieren más personal. En tanto servicio municipal, tienen restricciones impuestas por la legislación sobre contrataciones de las administraciones públicas y les resulta muy complicado incrementar el número de trabajadores sin intermediación de empresas privadas. Para C. Recios, aquello es un grave problema, pues las condiciones laborales de los trabajadores sujetos a diversas modalidades de contratación no son homogéneas y ello implica consecuencias en la coordinación cotidiana. Así, los problemas de organización de los servicios sociales se traducen en el exceso de trabajo para las asistentas. Las reuniones con los ciudadanos son menos frecuentes y la dificultad de realizar el seguimiento complica y ralentiza los procedimientos burocráticos. En las reuniones de las organizaciones sociales que trabajan por el derecho a la vivienda, como la Asociación 500x20 en Nou Barris, las personas en situación de emergencia habitacional expresan sus problemas en relación al trabajo de Servicios Sociales. Se observa un trato conflictivo entre las familias y las asistentas, generalmente debido a experiencias de discriminación y humillación hacia los demandantes de servicios sociales. Sin embargo, también se identifica el trabajo de asistentas sociales que permanecen muy atentas y vigilantes hacia ciertos casos y contribuyen a agilizar los trámites para que las personas logren conseguir todos los documentos necesarios para su inscripción en el Registro.

A través de las ayudas al pago del alquiler y otras medidas que inyectan dinero al mercado de viviendas, el Estado -por medio del Ayuntamiento- interviene de manera selectiva y no universal: ellas apuntan a las familias sin capacidad de integrarse a la sociedad de propietarios. Esta especialización se traduce en una espacialización de los recursos en algunos barrios que, como Nou Barris, concentran los problemas en el acceso a la vivienda ${ }^{127}$. De este modo, por medio de la generalización de las ayudas monetarias, se afianza un vínculo entre el Estado y la Administración local, pues ambas recurren a mecanismos distributivos -no universales- para contener

126 Entrevista con Carolina Recios.

127 Swyngedouw et al, 2014, p.151 
los problemas de acceso y mantenimiento en la vivienda. Es posible que las salidas monetarias permitan pensar el vínculo entre la escala local y nacional en términos de cooperación. Lo cierto es que se centra, desde la gestión local, en contener la avalancha de problemas socioeconómicos vinculados a la inestabilidad laboral, a la inestabilidad en la vivienda y la precarización de las condiciones de vida.

\section{El Ayuntamiento frente a la emergencia habitacional}

\section{La voluntad local por tratar el tema}

El Plan Nacional para la Promoción del Alquiler, la Rehabilitación de Edificios y la Regeneración Urbana 2013-2016 prevé financiamientos que las ciudades y comunidades autónomas pueden obtener a condición de presentar su candidatura ${ }^{128}$. La generalización de las asociaciones público-privadas está prevista en el Plan y el Estado reserva el financiamiento a las candidaturas que garanticen la realización de asociaciones con el sector privado, lo que complementa los recursos financieros para realizar las acciones propuestas ${ }^{129}$. El análisis de las políticas locales en materia de vivienda en Barcelona muestra una traslación de las orientaciones nacionales a la escala municipal. El Plan de Vivienda de Barcelona 2008-2016 promueve el mercado del alquiler a través del argumento de la disminución de precios de arrendamiento ${ }^{130}$. Fue efectivamente el caso entre 2008 y 2013, pero ya presentamos argumentos demostrando el alza del precio en el mercado del alquiler después del 2014.

Sin embargo, la ciudad no sufre el peso de las restricciones impuestas por el poder central. Ella tiene también su propio margen de maniobra. En el 2015, fue aprobada una Iniciativa Legislativa Popular (ILP) por el Parlamento de Cataluña: la Ley 24/2015 de medidas urgentes para afrontar la emergencia habitacional y la pobreza energética. Uno de los antecedentes de esta ley, también válida únicamente en el territorio catalán, es la Ley 18/2007 del derecho a la vivienda, la cual prevé la promoción de la vivienda pública en cesión de uso (a través de la participación de las cooperativas de vivienda) y el alquiler social ${ }^{131}$, así como la obligación de suprimir los usos anormales de las viviendas como las viviendas vacías o deshabitadas ${ }^{132}$. La Plataforma de Afectados por las Hipotecas (PAH) estuvo pendiente al origen de la Ley 24/2015, cuyo preámbulo describe la tragedia vivida por muchas familias que, tras la crisis, se encuentran desempleadas y sin manera de enfrentar las deudas hipotecarias. De igual manera, el texto reconoce la dificultad que tienen las familias para hacer frente a las facturas energéticas y afirma que la mayoría de expulsiones se deben al incumplimiento en los pagos del alquiler (67\% de los casos de expulsiones registrados en 2013$)^{133}$.

\footnotetext{
128 Plan Estatal para el fomento del alquiler de viviendas, la rehabilitación edificatoria y la regeneración y renovación urbanas, 2013-2016.

129 Id.Ibid

130 Oller, op.cit., p.116-118

131 Miralles Buil, 2015, p.169

132 Ley 24/2015 de medidas urgentes para hacer frente a la emergencia en materia de vivienda y pobreza energética.

133 Id.Ibid
} 
La ley reivindica la responsabilidad del Ayuntamiento para enfrentar la situación de emergencia en materia de vivienda. Esto es de crucial importancia, pues no hay una voluntad de transferencia de obligaciones hacia el Estado central o hacia otras dependencias públicas. De esta manera, la ley propone ocho medidas relativas a las expulsiones, entre ellas la protección a los consumidores, los procedimientos judiciales y extra-judiciales para resolver situaciones de sobre-endeudamiento y la supresión de los avales en casos de vínculos de parentesco. Otra de las proposiciones es la vía de la dación en pago, a través de la cual los deudores se quitan el peso de la deuda a cambio de la entrega de la vivienda. La ley prevé que, antes de la dación en pago, deben evaluarse otras opciones, sobre todo cuando las familias no tienen una alternativa residencial. El alquiler social debe ser propuesto por los grandes tenedores antes de proceder a acciones judiciales que puedan desembocar en expulsión. Los grandes tenedores están obligados a proponer un precio de alquiler igual a 10\% del ingreso de la unidad de convivencia cuando el ingreso mensual de ésta (considerando para ello la suma de los ingresos de todos los miembros) es inferior a 0.89 veces el IRSC ${ }^{134}$ (lo que equivale a $505.51 €$ ), 12\% de los ingresos cuando éstos son inferiores a 0.95 veces el IRSC (es decir, menos de $540.66 €$ ), y a $18 \%$ para las unidades de convivencia con ingresos que superen los $540.66 €$. Por ejemplo, si la unidad de convivencia adeuda a un gran tenedor, y cuenta con ingresos mensuales de $490 €$, le corresponde pagar (al gran tenedor) un alquiler mensual de $49 €$. Para las personas en riesgo de exclusión ${ }^{135}$ y que se encuentran alquilando en el mercado de viviendas (en este caso, no necesariamente vinculadas a grandes tenedores sino a pequeños propietarios), el Ayuntamiento se reclama responsable de impedir la pérdida de la vivienda, notablemente a través de las ayudas monetarias. La ley exige que el precio del alquiler no supere el 30\% del ingreso familiar mensual. Por ejemplo, si el alquiler mensual es de $700 €$ y la unidad de convivencia gana mensualmente $1000 €$, se considera el $30 \%$ de los ingresos totales (en este caso, 300€) y la diferencia es completada por el Ayuntamiento $(400 €)$ a condición de que la tarifa no exceda el precio promedio del barrio.

Algunos meses después de la aparición de esta ley 24/2015, la Comisión de Derechos Sociales de la gestión de Ada Colau publicó un documento titulado "Medidas urgentes para hacer frente a la emergencia habitacional y garantizar el derecho a la vivienda". Este documento retoma las orientaciones de la Ley 24/2015 y actualiza los datos relativos a las expulsiones. Entre junio del 2014 y junio del 2015, 2000 familias fueron expulsadas en Barcelona y en el 80\% de los casos la razón fue el impago de los alquileres. Nou Barris es mencionado como uno de los distritos más afectados (junto con Ciutat Vella y Sants Montjuic) y la Comisión establece que el Ayuntamiento

134 Índice de Renta de Suficiencia de Cataluña (IRSC), establecido en 569.12€ mensuales para el año 2015.

135 La ley define el riesgo de exclusión en relación al ingreso mensual de las unidades de convivencia: menos de 2 veces el IRSC (menos de $1138.24 €$ ) para las personas que viven solas, menos de 2.5 veces el IRSC ( $1422.8 €)$ para familias y menos de 3 veces el IRSC para las personas con movilidad reducida $(1707.36 €)$. 
es la autoridad encargada de realojar a las familias a través de la Mesa de Emergencia. El documento menciona la decisión de aumentar el presupuesto para la política de vivienda local en 11.1 M€ y especifica los cinco grandes ejes de acción de la nueva gestión local: la prevención de las expulsiones por impago de alquiler (a través de las ayudas monetarias), el realojamiento adecuado de las personas en situación vulnerable (movilizando para ello el derecho de expropiación para agrandar el parque de viviendas a destinación de la Mesa de Emergencia), promoción del alquiler social y otros regímenes de acceso a la vivienda (construcción anual de 1000 viviendas públicas), promoción de la función social de la vivienda (a través de campañas de sensibilización y multas a grandes tenedores) y, finalmente, la mejora de las condiciones residenciales (vía la rehabilitación) ${ }^{136}$. Se evidencia -también a escala localuna tendencia hacia la promoción de la vivienda pública en alquiler antes que en régimen de propiedad.

El diagnóstico que propone el documento concentra su atención en la enorme lista de espera de los inscritos en el Registro (28.550 unidades de convivencia, un total de 53.800 personas), donde la mayoría de familias están en situación de gran fragilidad. Asimismo, estos datos se cruzan con cifras de viviendas vacías: 31.200 en 2015, de las cuales 2.200 pertenecen a entidades financieras. Está claro que la gran cantidad de viviendas vacías es un problema en el contexto de demanda de vivienda en alquiler a precio asequible. Para los poderes públicos, también es una cuestión de dinamizar un mercado estancado (debido a que las viviendas vacías se encuentran fuera del mercado) en relación a los mercados de alquiler de otros países europeos. La ciudad de Barcelona recurre activamente al mercado del alquiler con el objetivo de responder a la demanda de vivienda y suplir la falta de parque público inmobiliario para alquilar a las familias en situación de emergencia residencial. Diversas acciones apuntan a negociar con los pequeños propietarios de viviendas vacías (pero también con los grandes tenedores de parque de viviendas) para convencerlos de introducir sus bienes al mercado. La Administración se compromete a rehabilitarlos (valorizarlos) a cambio de que la vivienda sea utilizable por una familia priorizada por la Mesa de Emergencia. El alquiler que deposita el Ayuntamiento oscila entre los 600 y 800 euros mensuales ${ }^{137}$.

Otras medidas movilizadas a escala local buscan activamente la participación de intermediarios privados (y del tercer sector) a fin de evitar la desconfianza de los propietarios hacia el Ayuntamiento. De esta manera, se explica el trabajo de Hábitat 3, un programa creado para el período 2014-2018, a cargo de negociar con los pequeños propietarios y los grandes tenedores la cesión de las viviendas al Ayuntamiento, el cual se compromete a habilitarlas y devolverlas en buen estado. Estas viviendas deben ser puestas a disposición de la Mesa de Emergencia para albergar a familias en situación de exclusión residencial. Hasta fines del 2015, 137 viviendas fueron

136 Ajuntament de barcelona, Mesures urgents per fer front a l'emergència habitacional i garantir el dret a l'habitatge, s/f.

137 Entrevista con Jaume Barnada. 
captadas por Hábitat 3 (de las cuales $42 \%$ requirieron renovación) ${ }^{138}$. Para resolver los problemas de captación, el Ayuntamiento decidió aumentar el presupuesto en 1.6 millones de euros (teniendo un presupuesto total de 5.662.800€) 139 $^{13}$.

De su lado, la Mesa de Emergencia es un mecanismo de evaluación que reúne una vez al mes a responsables de vivienda de la Generalitat de Cataluña y de la ciudad de Barcelona. Analizan los casos y documentos de los candidatos (en situación de exclusión residencial e inscritos en el Registro) y deciden quién obtendrá una vivienda a título provisional. Entre 2009 y 2015, solamente 1.260 viviendas fueron atribuidas por la Mesa de Emergencia y la evolución muestra un aumento de las atribuciones ( 75 en 2009, 177 en 2012, y 319 en 2015 ${ }^{140}$ ). La Mesa también está desbordada $^{141}$. La gran cantidad de demandas de vivienda a precio asequible obliga a la Administración a buscar otras alternativas en el mercado en función de las necesidades: número de miembros que componen la unidad de convivencia, distrito donde están escolarizados los niños, necesidades de las personas con movilidad reducida, etc. A la espera de encontrar las viviendas, la ciudad propone pensiones donde las personas pueden quedarse, lo cual resulta problemático debido a las estrictas condiciones de uso de estos lugares ${ }^{142}$. La Mesa trabaja en coordinación con Hábitat 3 y otras instituciones, tanto públicas como privadas. La participación de instituciones religiosas también es importante en la búsqueda de viviendas, sea para la compra o para el alquiler ${ }^{143}$. Es a través de las redes y las asociaciones público-privadas que la ciudad intenta compensar su insuficiente parque público de viviendas.

\section{La mediación como alternativa: la Administración frente a las expulsiones}

La principal razón por la cual las familias pierden sus viviendas a causa de expulsión son los procesos judiciales iniciados por impago de alquiler ${ }^{144}$. Frente a esta situación y en razón de las competencias municipales para impedir desalojos forzosos ${ }^{145}$, la actual gestión local busca prevenir las expulsiones. El 19 de enero de 2016 se anunció oficialmente la creación de la Unidad Contra la Exclusión Residencial (UCER), cuyos objetivos son evitar las expulsiones y reforzar la aplicación de la Ley 24/2015, incluidas las sanciones y multas a las entidades financieras que mantengan viviendas vacías. "Por consecuencia, ella [la UCER] será un soporte de los procedimientos

138 Datos del Consorci de l'Habitatge de Barcelona, Sessió Plenària, el 19/01/2016.

139 Id.Ibid

$140 \quad$ Id.Ibid

141 Entrevista con Carme Porta, mediadora de la UCER para el distrito de Nou Barris, el 25/01/2016.

142 Según información recogida en las asambleas de la Asociación 500x20, alojar a las familias en estas pensiones cuesta alrededor $90 €$ al día.

143 El presupuesto del Ayuntamiento prevé $26603694 €$ para la rehabilitación y $11800000 €$ para la compra de viviendas. Hasta fines de 2015, 150 viviendas fueron compradas por un total de $17300000 €$, fuera del costo de rehabilitación. La mayoría se sitúan en el distrito de Ciutat Vella (112 viviendas) y luego en el distrito de Sant-Andreu (22 viviendas). En el distrito de Nou Barris, se compraron 12 viviendas.

144 Ajuntament de Barcelona, Mesures urgents per fer front a l'emergència habitacional i garantir el dret a l'habitatge, s/f.

145 Alemany et al, 2013, p.46 
de sanción de la ciudad hacia prácticas irregulares de grandes tenedores de vivienda, y los forzará a proponer alquiler social, opción que no ofrecen a fin de lograr la expulsión"146. Hasta fines de 2015, 13 grandes tenedores propusieron viviendas en alquiler social y se realizaron 1400 solicitudes de puesta a disposición de las viviendas vacías, aunque sin resultados ${ }^{147}$.

Las trece personas que conforman la UCER tienen perfiles diversos: abogados, especialistas en tareas administrativas, etc. Su trabajo cotidiano implica la discusión y negociación directa con propietarios a fin de lograr soluciones, centralización de la información y coordinación con diferentes instituciones públicas a cargo de la gestión de vivienda (fundamentalmente la Oficina de Vivienda y los Servicios Sociales $)^{148}$. Este trabajo está de alguna manera prefigurado en la Ley 4/2013 de medidas de flexibilización y fomento del mercado del alquiler de viviendas. Dicha ley introduce el recurso a la mediación para que las partes (inquilinos y propietarios) puedan resolver sus diferencias sin necesidad de llegar a procesos judiciales ${ }^{149}$. Sin embargo, esta ley apuntaba a buscar la mediación en el mercado. En todo caso, ella no proponía responsabilizar a la gestión local de esa tarea. En el caso de Barcelona, es el Ayuntamiento el que decide tomar las riendas de la mediación y asumir la prestación de este servicio, el cual es finalmente gratuito para los inquilinos y los propietarios. Se trata del reconocimiento de un problema público, cuya contestación y gestión recaía exclusivamente en las organizaciones sociales defensoras del derecho a la vivienda.

A pesar de que la presentación oficial muestra a la UCER como creación de la actual gestión local ${ }^{150}$, los entrevistados manifiestan que tal mecanismo de mediación ya existía en el mandato precedente ${ }^{151}$. La actual gestión refuerza la iniciativa a través de la asignación de personal a cargo y la creación de una institución específica. Entonces, podemos afirmar que es un reciclaje que se mantiene por la reformulación y el refuerzo de un instrumento ${ }^{152}$. La ruptura simbólica que se opera es importante ${ }^{153}$; se observa en los valores introducidos y promovidos por los mediadores en su trabajo cotidiano. La implicación emocional de los mediadores en la resolución de los casos se explica, en parte, por la trayectoria militante de algunos miembros de la UCER. Así, por ejemplo, Carme Porta es mediadora en el distrito de Nou Barris y realizó este trabajo voluntariamente desde la PAH, antes de ser contratada por el Ayuntamiento. C. Porta reconoce que esta labor, ahora realizada desde el gobierno local, fue asumida durante muchos años por las organizaciones sociales, como la PAH y la Asociación 500x20. El hecho de realizar actualmente la

146 Ajuntament de Barcelona, Barcelona crea una unitat d'actuació preventiva per aturar desnonaments i lluitar contra l'exclusió residencial, 19 de enero de 2016.

147 Datos del Consorci de l'Habitatge de Barcelona, Sessió Plenària 19/01/2016.

148 Ajuntament de Barcelona, op.cit.

149 Pérez Conesa, 2013, p.24

150 Id.Ibid

151 Entrevista con Jaume Barnada y Carme Porta.

152 Le Galès y Lascoumes, 2004

153 Id., p.358 
mediación desde el Ayuntamiento proporciona mayor legitimidad y fuerza a la defensa contra la expulsión, notablemente frente a los pequeños propietarios, pero principalmente frente a los grandes tenedores. Éstos trabajan con recuperadores, es decir, personas a cargo de hacer la negociación con los ocupantes de la vivienda para que la abandonen. Los mediadores de la UCER confrontan a los recuperadores de los bancos exigiendo respeto por lo que establece la Ley 24/2015. Asimismo, obligan a los recuperadores a proponer un alquiler social a las familias en riesgo de exclusión residencial. Frente a las entidades financieras, la estrategia apunta primero a retrasar la fecha de expulsión y ganar tiempo para que el Ayuntamiento pueda negociar la oferta de alquiler social o, en el caso contrario, para que la ciudad encuentre una alternativa residencial para las familias.

El intenso trabajo cotidiano de los mediadores expresa la voluntad de renovar la acción pública a escala local. A través de su presencia en el terreno y su proximidad con las familias, se afirma una imagen de la Administración como una institución próxima y de lado de los ciudadanos. La UCER tiene como meta que ninguna familia se quede en la calle ${ }^{154}$. Sin embargo, el hecho de detener las expulsiones desde el Ayuntamiento no implica la reducción de procesos judiciales destinados a terminar en expulsión. Pese a la importancia del trabajo de los mediadores, mantenerse en una vivienda alquilada continúa siendo un problema para las familias en situación de precariedad económica. Los datos sobre evolución de tipo de consulta realizada a los servicios jurídicos de la red de Oficinas de Vivienda muestran que la mayoría de demandas conciernen a problemas de alquiler ${ }^{155}$.

Los mediadores, en tanto que agentes de servicio municipal (street-level bureaucrates), realizan acciones inmediatas y personales, individualmente ${ }^{156}$. Tres situaciones mayores se presentan en el trabajo de los mediadores: gestionar los casos de expulsión de los inquilinos deudores, de las personas con deudas hipotecarias y los casos de ocupaciones ilegales. Como instrumento relativamente nuevo, el margen de maniobra que poseen los mediadores está siendo explorado cotidianamente. Su tarea principal es la de ser intermediarios entre diferentes actores privados y el gobierno local, pero también lidian con otras instituciones públicas como el Tribunal de Justicia, básicamente para que las expulsiones puedan ser aplazadas ${ }^{157}$. La falta de certeza sobre la posibilidad de disponer de ayuda monetaria o de viviendas para las familias desesperadas ante la inminencia del desalojo y la pérdida de su hogar

154 Entrevista con Carme Porta.

155 No tenemos información más precisa para poder determinar si las consultas son hechas por pequeños propietarios o más bien por inquilinos. Fuente: datos del Consorci de l'Habitatge de Barcelona, op.cit.

156 Lipsky, 2011, p.8

157 Entrevista con Carme Porta y entrevista con Llorens, activista de la PAH-Barcelona, realizada en el distrito de Sants el 15/12/15. 
produce que en varias ocasiones se encuentren en situaciones muy difíciles de manejar, tanto frente a las familias como frente al Ayuntamiento.

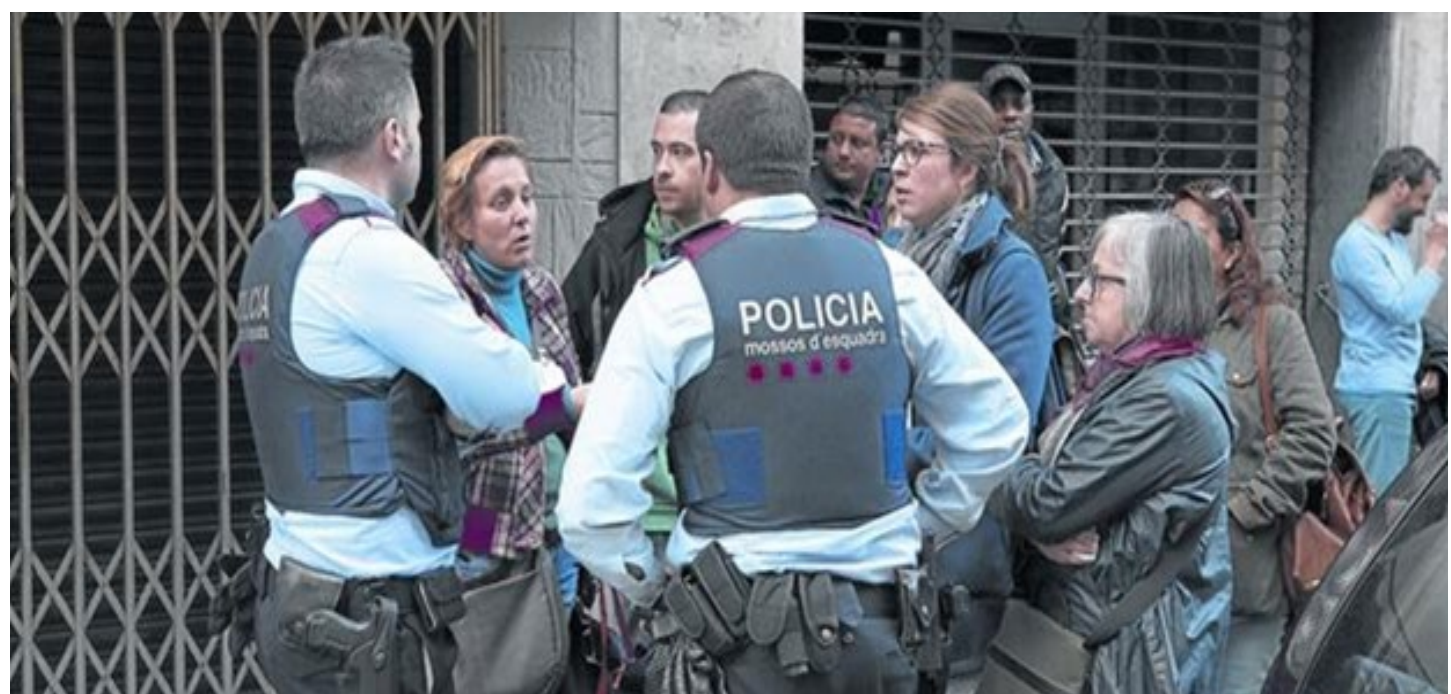

Figura 3. Carme Porta, mediadora de la UCER para el distrito de Nou Barris.

Fuente: Josep García, El Periódico, 27/04/2016

A diferencia de los inquilinos deudores, para los cuales se dispone un protocolo de acción más o menos claro, el Ayuntamiento aún no sabe qué hacer en relación a los ocupas. En algunos casos, la ocupación de la vivienda se ha realizado con complicidad de los vecinos, pero en los casos en que esto no sucede los ocupas intentan ser silenciosos e invisibles ${ }^{158}$ para poder permanecer en el inmueble ${ }^{159}$. Como lo recuerda Thomas Aguilera en su estudio sobre los ocupas de Paris y Madrid, la ocupación es generalmente ignorada por el gobierno local ( sin que esto implique el desconocimiento del fenómeno) hasta el momento en que una situación de urgencia aparece como detonadora ${ }^{160}$. El Ayuntamiento teme que la ocupación termine por distorsionar el mercado, por ejemplo, al reforzar el sentimiento de desconfianza de los pequeños propietarios frente al mercado de alquiler. Al mismo tiempo, la búsqueda de soluciones desde el gobierno local apunta a que los ocupas demuestren que se encuentran en situación de exclusión residencial para que se pueda proponer alguna alternativa vía el Registro de solicitantes de vivienda. Para los mediadores, resulta determinante saber si la vivienda ocupada pertenece a pequeños o a grandes tenedores. En caso de ser vivienda de pequeños propietarios, el Ayuntamiento no puede impedir el desalojo, pues se trataría de dos familias que están siendo perjudicadas (por un lado, los ocupas y, por otro, los propietarios). En este caso, la mediación

158 Aguilera, 2014

159 Thomas Aguilera emplea el término ocupas silenciosos (squats discrets) para hablar de las familias precarizadas, del tráfico organizado y de las iniciativas individuales que buscan generalmente no llamar la atención sobre su presencia en las viviendas para así poder quedarse (Aguilera, op.cit.).

160 Id., p.10 
buscará que la familia ocupa se inscriba en el Registro e inicie la solicitud de vivienda social. Cuando las ocupaciones se originan en propiedad de grandes tenedores, la mediación buscará aplazar la expulsión y acompañar a la familia en los trámites necesarios para regularizar su situación e inscribirse al Registro. En paralelo, la negociación con los grandes tenedores busca ofrecer un alquiler social para las familias, lo que resulta generalmente en una solución favorable al Ayuntamiento. Los bancos evitan las expulsiones en invierno y prefieren negociar con las autoridades públicas en un esfuerzo por cuidar su imagen en la prensa local y nacional ${ }^{161}$. Sin embargo, cuando la negociación no resulta favorable al Ayuntamiento y la expulsión es inminente, los mediadores llaman a las organizaciones sociales para que la movilización ciudadana pueda presionar -mediática y colectivamente- a los bancos y evitar la expulsión.

En el caso de Nou Barris, las organizaciones sociales están integradas, de alguna manera, al funcionamiento de la UCER. La estrecha coordinación entre los mediadores y los activistas es fundamental y el rol de estos últimos continúa teniendo un peso muy importante para resolver problemas vinculados al impago de alquiler. De hecho, la eficacia del instrumento depende de la movilización ciudadana y de la calidad y rapidez en la comunicación entre las organizaciones sociales y los mediadores. En Nou Barris, por ejemplo, la Asociación 500x20 mantiene una estrecha coordinación con los mediadores y comunica sobre los casos que se presentan y que llegan primero, por lo general, al espacio asambleario de la Asociación antes que a las Oficinas de Vivienda del Ayuntamiento. Así, 500x20 es un puente entre las familias en riesgo de exclusión residencial y el gobierno local. De su lado, la UCER también brinda rápidamente información sobre el estado de las gestiones (si logró detenerse algún desahucio o qué etapa del proceso continúa) frente a los grandes tenedores, frente al Ayuntamiento o a pequeños propietarios. Las organizaciones sociales reservan la movilización colectiva para los casos en que la UCER no puede detener la expulsión. Mientras tanto, en los espacios asamblearios las demandas en materia de vivienda pública siguen su curso, formulándose y redefiniéndose.

\section{Conclusiones}

No ha sido nuestra intención presentar una lista exhaustiva de los esfuerzos que vienen desplegándose desde el Ayuntamiento de Barcelona por garantizar el derecho a la vivienda. Presentamos a la UCER como política alternativa en la regulación local debido a que ella cumple con la definición ideal-tipo propuesta por Vincent Béal y Max Rousseau en tanto es una iniciativa emergida ante la exigencia de los movimientos sociales, así como una alternativa que no responde a

161 Entrevista con Carme Porta y entrevista con Toni Tallada, activista de 500x20 y elegido conseller por el distrito de Nou Barris (partido Barcelona En Comú), realizada en el Centre Comunitari Porta, distrito de Nou Barris, el 10/12/15. 
una receta impuesta con problemas de adecuación a la realidad social local. Antes bien, ella se adapta a una forma de resolver problemas de vivienda ya ensayada por las organizaciones sociales. El estudio de esta joven e interesante iniciativa nos permite complementar $y$, de esta manera, ampliar un ideal normativo de política urbana alternativa progresista por su componente temporal (progresivamente, paso por paso) y por su búsqueda de justicia social. Entonces, las políticas urbanas alternativas:

1. Lejos de evadir competencias o transferir responsabilidades a otras escalas de gobierno, buscan ganar margen de maniobra, absorber y ampliar competencias para tener mejores herramientas con las cuales limitar y erradicar la precarización de las condiciones de vida de la población. Se busca combatir en el terreno legislativo, como sucedió con la ILP 24/2015 aprobada por el parlamento catalán.

2. Ante la contestación y movilización social, reconocen un problema como público, de interés general, sin evadir responsabilidades frente a la ciudadanía y las organizaciones sociales. Éstas han sido históricamente responsables de suplir con su trabajo los vacíos producto de la ausencia estatal, regional o local, al punto que las administraciones han dependido del trabajo de la sociedad civil organizada para canalizar el gasto público hacia inversiones rentables. Entonces, las políticas urbanas alternativas se responsabilizan de problemas largamente ignorados por la Administración y contribuyen a que las organizaciones sociales sigan avanzando en sus reivindicaciones.

3. Se inspiran y aprenden del repertorio de acciones y estrategias de las organizaciones sociales, quienes se han especializado en la gestión y resolución de ciertos problemas. Este aprendizaje implica que el Ayuntamiento esté presente en la calle, en acciones reivindicativas y de protesta, en espacios asociativos, y promueva la comunicación con los vecinos sin atentar contra la independencia de sus organizaciones.

Hemos visto que la configuración de la política de vivienda en España condiciona la acción de la Administración local a la búsqueda de intersticios desde los cuales contestar las injusticias, detenerlas y reducirlas progresivamente. La regulación de la emergencia habitacional por el Ayuntamiento de Barcelona está limitada por diversos frentes y la dualidad de la política de vivienda -expresada en la diferenciación de competencias sociales y económicas- es un freno que urge desatascar. Se trata de que el Ayuntamiento pueda regular la emergencia habitacional y sostener la política de vivienda de manera integral con los recursos suficientes para garantizar un derecho fundamental, pero no todo es conflicto entre las diferentes escalas de gobierno y tampoco es entre ellas que se encuentran los principales problemas de coordinación. Por el contrario, las diferentes escalas cooperan en muchos aspectos y, prueba de ello, es la existencia del Consorci de vivienda (que vincula al Ayuntamiento de Barcelona con la Generalitat de Catalunya) así como la convergencia de las orientaciones políticas nacionales en el Plan Municipal de Vivienda 2008-2016. Sobre este último punto, ciertamente la adecuación responde a la necesidad local 
por garantizar fondos públicos para el desarrollo de las operaciones y programas como sucede con la promoción del mercado del alquiler, a manera de respuesta a la emergencia habitacional. Sin embargo, como instrumento de gestión pública, también expresa convergencia programática, política. Ciertamente, la regulación local en materia de políticas de vivienda delata continuidades en lo relativo a las alianzas público-privadas, como la búsqueda de soluciones a la emergencia habitacional en el mercado inmobiliario de alquiler. A pesar de ello, no podemos ser mezquinos y eclipsar del análisis el despliegue de esfuerzos que se dirigen hacia otra dirección y responden a las injusticias sociales. Barcelona tiene otra oportunidad histórica para transformar la ciudad desde la dialéctica relación entre las políticas urbanas y la movilización social.

\section{Bibliografía}

AGUILERA, Thomas. L'inaction publique face aux squatts discrets à Paris et à Madrid. Métropoles. [En línea]. $24 \mathrm{~d}$

e junio de 2014, n. ${ }^{\circ}$ 14. <https://metropoles.revues.org/4860>. [ 5 de febrero de 2016]. ISSN: 1957-7788

ALEMANY, Adrià et al. Emergencia habitacional en el Estado español. La crisis de las ejecuciones hipotecarias y los desalojos desde una perspectiva de derechos humanos. Barcelona: Observatori DESC y PAH, 2013. 146 p.

ALGABA, Antonio. La discriminación en el acceso al mercado de la vivienda: las desventajas de la inmigración. Novedades y permanencias. Scripta Nova, Revista Electrónica de Geografía y Ciencias Sociales. [En línea]. Barcelona: Universidad de Barcelona, 1 de agosto de 2003, vol. VII, núm. 146 (60). <http://www.ub.edu/geocrit/sn/ sn-146(060).htm>. [02 de octubre de 2015]. ISSN: 1138-9788.

ÁLVAREZ, Arturo. El desahucio arrendaticio como instrumento de política económica: Del "desahucio express" al juicio monitorio de desahucio. In COLINA, Rafael (dir.). La protección del arrendador como instrumento para dinamizar el mercado del alquiler de viviendas. Perspectivas desde la reforma. Navarra: Editorial Aranzadi, 2014, p.719-788

ARENDS, Lenimar. Vivienda social en España. Barcelona: Universidad Politècnica de Catalunya, 2012

BARCELÓ, Mercè y VINTRÓ, Joan (coords.). Dret Públic de Catalunya. Barcelona: Codecs Editorial, 2003

BAYONA, Jordi. La segregación residencial de la población extranjera en Barcelona: ¿una segregación fragmentada?. Scripta Nova, Revista Electrónica de Geografía y Ciencias Sociales. [En línea]. Barcelona: Universidad de Barcelona, 15 de marzo de 2007, vol. XI, núm. 235. <http://www.ub.es/geocrit/sn/sn-235.htm>. [03 de marzo de 2016]. ISSN: 1138-9788.

BAYONA, Jordi; PUJADAS, Isabel y RUBIALEES, Miguel. Patrones espaciales de la segregación residencial en la Región Metropolitana de Barcelona: pautas de segregación de los grupos altos. Scripta Nova, Revista Electrónica de Geografía y Ciencias Sociales. [En línea]. Barcelona: Universidad de Barcelona, 20 de diciembre de 2012, Vol. XVI, no.423. <http://www.ub.edu/geocrit/sn/sn-423.htm>. [03 de octubre de 2015]. 
ISSN: $1138-9788$.

BÉAL, Vincent. Does neoliberalisation matter? Apports et limites d'une notion montante des urban studies dans la science politique francaise. Working paper du programme "Villes et Territoires". [En línea]. Paris : Sciences Po, 11 de mayo de 2010, nº $1 .<\mathrm{http}: / /$ blogs.sciences-po.fr/recherche-villes/beal-vincent-2010-\%c2\%ab-does-neoliberalisation-matter-apports-et-limites-d \% e 2\% 80\%99une-notion-montante-des-urban-studies-dans-la-science-politique-francaise-\%c2\%bb/>. [ 18 de diciembre de 2015].

BÉAL, Vincent y ROUSSEAU, Max. Alterpolitiques!. Métropoles. [En línea]. 15 de diciembre de 2014, $\mathrm{n}^{\circ} 15$. <http://metropoles.revues.org/4948>. [ 14 de enero de 2015]. ISSN: 19577788 .

BENACH, Nuria y TELLO, Rosa. En los intersticios de la renovación. Estrategias de transformación del espacio y flujos de población en Barcelona. Revista de Geografía, 2004, n³, p.93-114

BETANCOR, Andrés. Economía y Hacienda. In DEL CAMPO, Salustiano y TEZANOS, José Félix (dir.). España Siglo XXI, Vol.2. Madrid: Editorial Biblioteca Nueva, 2008, p.223-244

BLANCO, José A. Comentarios a la ley de arrendamientos urbanos. Madrid: Difusión Jurídica y temas de Actualidad, 2006

BORJA, Jordi. Luces y sombras del urbanismo en Barcelona. Barcelona: Editorial UOC, 2010 .

BRENNER, Neil y THEODOR, Nik. Cities and the Geographies of "Actually Existing Neoliberalism". Antipode, 2002, vol. 34, issue 3, p.349-379

BRENNER, Neil. New State Spaces. Urban Governance and the Rescaling of Statehood. Oxford: Oxford University Press, 2004

BUSQUETS, Joan. Barcelona. Rovereto: Nicolodi, 2005

CAPEL, Horacio. Los inmigrantes en la ciudad. Crecimiento económico, innovación y conflicto social. Scripta Nova, Revista Electrónica de Geografía y Ciencias Sociales. [En línea]. Barcelona: Universidad de Barcelona, 1 de mayo de 1997, n³. <http://www.ub.edu/geocrit/ sn-3.htm>. [10 de octubre de 2015]. ISSN: 1138-9788.

CAPEL, Horacio. Inmigrantes extranjeros en España. El derecho a la movilidad y los conflictos de la adaptación: grandes expectativas y duras realidades. Scripta Nova, Revista Electrónica de Geografía y Ciencias Sociales. [En línea]. Barcelona: Universidad de Barcelona, 1 de febrero de 2001, no81. <http://www.ub.edu/geocrit/sn-81.htm>. [ 10 de octubre de 2015]. ISSN: 1138-9788.

CAPEL, Horacio. ¿En qué ha fallado Barcelona?. Finisterra. Revista Portuguesa de Geografía, 2010, vol. 45, nº 90, p.173-204

CAPEL, Horacio. La morfología de las ciudades, Tomo III. Agentes urbanos y mercado inmobiliario. Barcelona: Ediciones del Serbal, 2013.461 p.

DIAZ, Ramón; DOMÍNGUEZ, Josefina y PARREÑO, Juan Manuel. Inmigración y ciudad en España: integración versus segregación socio-territoriales. Scripta Nova, Revista Electrónica de Geografía y Ciencias Sociales. [En línea]. Barcelona: Universidad de Barcelona, 1 de agosto de 2010, Vol. XIV, núm. 331 (50). <http://www.ub.edu/geocrit/sn/sn-331/sn331-50.htm>. [10 de octubre de 2015]. ISSN: 1138-9788. 
EQUIP EARHA, Infrahabitatge a Catalunya. Scripta Nova, Revista Electrónica de Geografía y Ciencias Sociales. [En línea]. Barcelona: Universidad de Barcelona, 1 de agosto de 2003, vol. VII, n ${ }^{0} 146$ (049). <http://www.ub.edu/geocrit/sn/sn-146(049).htm>. [03 de febrero de 2016]. ISSN: 1138-9788.

FERRER, Amador. El Pla General Metropolità de Barcelona. La versió de 1976. In Els 20 anys del Pla General Metropolità de Barcelona. Barcelona: Instituto d'Estudis Metropolitans de Barcelona, 1997, p.45-54

FABRE, Jaume y HUERTAS, Josep. Tots els Barris de Barcelona, Tomo VII, Els Polygons (2) i el Districte Cinquè. Barcelona: Edicions 62, 1977

FIJALKOW, Yankel. Sociologie du logement. Paris: La Découverte, 2016

GARCÍA, Inmaculada. La protección legal de los derechos del arrendador antes y después de la reforma de la ley de arrendamientos urbanos (Ley 4/2013, de 4 de junio). In COLINA, Rafael. La protección del arrendador como instrumento para dinamizar el mercado del alquiler de viviendas. Perspectivas desde la reforma. Navarra: Editorial Aranzadi, 2014, p.677717

GÁZQUEZ, Laura. Cláusulas arbitrales y el contrato de arrendamiento urbano. In COLINA, Rafael. La protección del arrendador como instrumento para dinamizar el mercado del alquiler de viviendas. Perspectivas desde la reforma. Navarra: Editorial Aranzadi, 2014, p. 553-598

GUARRO, Beatriu. La discriminación de las personas inmigradas en el acceso a la vivienda. In TELLO, Rosa y PÉREZ-RINCÓN, Socorro (eds.). ¿Derecho a la vivienda? Miradas críticas a las políticas de vivienda. Barcelona: Ediciones Bellaterra, 2012, p.51-62

HARVEY, David. From Managerialism to Entrepreneurialism: The Transformation in Urban Governance in Late Capitalism. Geografiska Annaler B, 1989, vol.71, n¹, p.3-17

HARVEY, David. Breve historia del Neoliberalismo. Madrid: Akal, 2007

HERRERA, Tania. On a le droit mais pas d'argent. Les stratégies d'accès au logement à Barcelone. Mémoire de Master 2 Recherche dirigida por Christelle Morel-Journel. Saint-Étienne: Université Jean Monnet- Université de Lyon, 2016. 131p.

JESSOP, Bob. Liberalism, Neoliberalism, and Urban Governance: A State-Theoretical Perspective. Antipode, 2002, vol.34, issue 3, p.452-472

LASCOUMES, Pierre y LE GALÈS Patrick. Gouverner par les instruments. Paris: Presses de la Fondation Nationale des Sciences Politiques, 2004

LASCOUMES, Pierre y LE GALÈS Patrick. Sociologie de l'action publique. Paris: Armand Colin, 2012

LE GALÈS, Patrick. Neoliberalism and Urban Change: Stretching a Good Idea Too Far?. Territory, Politics, Governance, 2016, Vol.4, issue 2, p.154-172

LEFEBVRE, Henri. Le droit à la ville. 3ra edición. Paris: Anthropos, 2009. 135 p.

LIPSKY, Michael. Street-level bureaucracy. Dilemmes of the Individual in Public Services. New York: Russell Sage Foundation, 2010

LÓPEZ, Isidro y RODRÍGUEZ, Emmanuel. Fin de ciclo. Financiarización, territorio y sociedad de propietarios en la onda larga del capitalismo hispano (1959-2010). Madrid: Traficantes de sueños, 2010

NAREDO, José Manuel. El modelo inmobiliario español y sus consecuencias. Comuni- 
cación al Coloquio sobre Urbanismo, democracia y mercado: una experiencia española (19702010), Institut d'Urbanisme de Paris, Université de Paris 12 Val-de-Marne, Escuela T.S. de Arquitectura de Madrid, Casa de Velásquez, Paris, 2010.

MARRE, Diana. Reflexiones desde la "minoría" al artículo Inmigrantes extranjeros en España de Horacio Capel. Scripta Nova, Revista Electrónica de Geografía y Ciencias Sociales. [En línea]. Barcelona: Universidad de Barcelona, 20 de marzo de 2001, nº85. <http://www.ub.edu/geocrit/sn-85.htm\#diana>. [21 de diciembre de 2015]. ISSN: $1138-9788$.

MARRERO, Isaac. ¿Del Manchester catalán al Soho barcelonés? La renovación del barrio del Poblenou en Barcelona y la cuestión de la vivienda. Scripta Nova, Revista Electrónica de Geografía y Ciencias Sociales. [En línea]. Barcelona: Universidad de Barcelona, 1 de agosto de 2003, no 146 (137). <http://www.ub.edu/geocrit/sn/sn-146(137). htm>. [17 de diciembre de 2015]. ISSN: 1138-9788.

MAURY, Yann. Le logement social dans quatre métropoles Européennes: Londres, Rome, Berlin et Barcelone. Le rôle des associations, 2001 Plus, Nº66, 2006

MIRALLES-BUIL, Diego. Les coopératives d'habitation en cession d'usage à Barcelone. Mémoire de Master 2 Recherche, Lyon: Université Lumière Lyon 2, 2015, 200p.

MOREL JOURNEL, Christelle y PINSON, Gilles. The neoliberal City-Theory, Evidence, Debates. Territory, Politics, Governance, Vol. 4, issue 2, 2016, p.137-153

ORDUÑA, Enrique. Historia del Municipalismo Español. Madrid: Iustel, 2005

PAQUOT, Thierry. "Habitat, habitation, habiter" Ce que parler veut dire... Informations sociales, 2005, $3 \mathrm{n}^{\circ} 123, \mathrm{p} .48-54$

PAREJA-EASTAWAY, Montserrat y SÁNCHEZ-MARTÍNEZ, Teresa. Vivienda y cambio social en España. In TELLO, Rosa y PÉREZ-RINCÓN, Socorro (eds.). ¿Derecho a la vivienda? Miradas críticas a las políticas de vivienda. Barcelona: Ediciones Bellaterra, 2012, p. $113-$ 139

PECK, Jamie y TICKELL, Adam. Neoliberalizing Space. Antipode, 2002, vol.34, issue 3, p.380-402

PÉREZ CONESA, Carmen. Arrendamientos de vivienda y desahucios: su reforma. Estudio de las modificaciones introducidas por la Ley 4/2013, de 4 de junio. Navarra: Aranzadi, 2013

RIOL, Eduardo. La vivienda de los inmigrantes en Barcelona: el caso del colectivo pakistaní. Scripta Nova, Revista Electrónica de Geografía y Ciencias Sociales. [En línea]. Barcelona: Universidad de Barcelona, 1 de agosto de 2003, Vol. VII, n. ${ }^{o} 146$ (059).<http://www.ub.edu/ geocrit/sn/sn-146(059).htm>. [10 de octubre de 2015]. ISSN: 1138-9788.

RODRIGUEZ LÓPEZ, Julio. Las políticas de vivienda social desde el postfranquismo. In VILANOVA, Josep M. y CASALS, Vicenç (eds.). Habitatge i societat a la Catalunya del segle XXI. [sin datos de lugar y fecha], p.25-35

RUIPÉREZ, Javier. El derecho constitucional a la vivienda y la problemática de su arrendamiento en el Estado Social. In COLINA, Rafael. La protección del arrendador como instrumento para dinamizar el mercado del alquiler de viviendas. Perspectivas desde la reforma. Navarra: Editorial Aranzadi, 2014, p.29-183

SERRATOSA, Albert. La revisió del Pla Comarcal de 1953: Alternatives a l'origen i or- 
ganització dels treballs. In Els 20 anys del Pla General Metropolità de Barcelona. Barcelona: Instituto d'Estudis Metropolitans de Barcelona, 1997, p.11-14

STORPER, Michel. The Neo-liberal City as Idea and Reality, Territory, Politics, Governance, 2016, Vol.4, Issue 2, p. 241-263

SWYNGUEDOUW, Erik, MOULAERT, Frank y RODRIGUEZ, Arantxa. L'urbanisation néolibérale en Europe : grands projets urbains et nouvelle politique de la ville. In GINTRAC, Cécile y GIROUD, Matthieu. Villes contestées. Pour une géographie critique de l'urbain. Paris: Les prairies ordinaires, 2014, p.143-161

TATJER, Mercè. Burgueses, inquilinos y rentistas. Mercado inmobiliario, propiedad y morfología en el centro histórico de Barcelona: La Barceloneta. Madrid: Consejo Superior de Investigaciones Científicas, 1988

TATJER, Mercè. La Trinitat Nova, Barcelona. Barcelona: Generalitat de Catalunya, 1995a

TATJER, Mercè. Urbanització Meridiana, Barcelona. Barcelona: Generalitat de Catalunya, $1995 \mathrm{~b}$

TATJER, Mercè. La vivienda obrera en España de los siglos XIX y XX: de la promoción privada a la promoción pública (1853-1975), Scripta Nova, Revista Electrónica de Geografía y Ciencias Sociales. [En línea]. Barcelona: Universidad de Barcelona, 1 de agosto de 2005, Vol.IX, n¹94 (23). <http://www.ub.edu/geocrit/sn/sn-194-23.htm>. [03 de marzo de 2016]. ISSN: 1138-9788.

TATJER, Mercè. Polítiques d'habitatge social durant el franquisme. In VILANOVA, Josep M. y CASALS, Vicenç (eds.). Habitatge i societat a la Catalunya del segle XXI. [sin datos de lugar yfecha], p. 15-23

TELLO, Rosa. Políticas públicas de vivienda en Barcelona y Ciudad de México. In TELLO, Rosa y PÉREZ-RINCÓN, Socorro (eds.). ¿Derecho a la vivienda? Miradas críticas a las políticas de vivienda. Barcelona: Ediciones Bellaterra, 2012, p.207-224

TELLO, Rosa y MARTINEZ, Sergi. Terciarización y encarecimiento de la vivienda en Barcelona. Revista de Geografía, vol.XXIX, n²2, jul-sept, 1995, p.41-51

TRILLA, Carme. El Pacte Nacional per a l'Habitatge i els agent socials i econòmics. In VILANOVA, Josep M. y CASALS, Vicenç (eds.). Habitatge i societat a la Catalunya del segle XXI. [sin datos de lugar y fecha], p. 37-43

VILANOVA, Josep M. La renovación del espacio residencial: estrategias y políticas de intervención en Barcelona. Coloquio sobre "El desarrollo urbano de Montréal y Barcelona en la época contemporánea: estudio comparativo". Universidad de Barcelona, 5-7 de mayo de 1997.

VORMS, Charlotte. Surproduction immobilière et crise du logement en Espagne. La Vie des Idées. [En línea]. Paris: Collège de France, 12 de mayo de 2009. <http://www.laviedesidees.fr/Surproduction-immobiliere-et-crise.html>. [03 abril de 2016]. ISSN: 2105-3030.

\section{Documentos públicos y reportes}

AJUNTAMENT DE BARCELONA, Evolució de l'atur registrat a Barcelona [en línea], 2015. $<$ http://w27.bcn.cat/porta22/images/cat/Barcelona_Treball_Atur_Bcn_Oct_2015_avanc_ cat_tcm9-40070.pdf>. [18 de noviembre de 2015]

AJUNTAMENT DE BARCELONE, Mesures urgents per fer front a l'emergència habitacional 
i garantir el dret a l'habitatge. Comissió de drets socials, cultura i esports, 21 de setiembre de 2015.

AJUNTAMENT DE BARCELONA, Normes reguladores del funcionament dels districtes.

BARNADA, Jaume y FAJARÍ, Lluís (coord.). Pla d'Habitatge de Barcelona 2008-2016. Barcelona: Ajuntament de Barcelona, 2009

CONSORCI DE L'HABITATGE DE BARCELONE, Mémoria 2013, s/f

CONSORCI DE L'HABITATGE DE BARCELONE, Registre de sol-licitants d'habitatge amb protecció oficial de Barcelona, Informe de Situació a 31/12/2015 de BARCELONA i DISTRICTE DE NOU BARRIS, Activitat del Servei i Adjudicacions des de l'any 2009 al 2015, informe elaborat el 8/2/2016. [Información sujeta a demanda].

CONSORCI DE L'HABITATGE DE BARCELONA, Consell de l'Habitatge Social de Barcelona, Sessió Plenària del 19/01/2016

CONSORCI DE L'HABITATGE DE BARCELONA, Conveni de Col.laboració entre el consorci de l'habitatge de Barcelona i la Societat Municipal Barcelona Gestió Urbanistica, Societat Anonima per a la gestió integral de les oficines d'habitatge de Barcelona durant l'any 2015 [en línea], 2015. <http://www.bcn.cat/consorcihabitatge/es/files/Amb_Barcelona_Gestio_Urbanistica_SA_2015.pdf>. [6 de noviembre de 2015].

MINISTERIO DE LA PROMOCIÓN, Plan Estatal de fomento del alquiler de viviendas, la rehabilitación edificatoria, y la regeneración y renovación urbanas, 2013-2016 [en línea]. <http:// www.fomento.gob.es/MFOM/LANG_CASTELLANO/DIRECCIONES_GENERALES/ARQ_VIVIENDA/APOYO_EMANCIPACION/PLAN_ESTATAL.htm>. [9 de junio de 2016].

OLLER, Glòria (coord.). L'habitatge a Barcelona 2008-2010. Pla d'Habitatge a Barcelona 2008-2016 [en línea]. Barcelona: Ajuntament de Barcelona e Institut Municipal d'Urbanisme, s/f. <http://ajuntament.barcelona.cat/dretssocials/sites/default/files/arxius-documents/pla-habitatge-Barcelona-2008-2016.pdf>. [ 18 de noviembre de 2015].

PATRONATO MUNICIPAL DE L'HABITATGE DE BARCELONA, Plan BARCELONA 20082016

\section{Textos legislativos}

Ley 49/1960, de 21 de julio, sobre propiedad horizontal. Agencia Estatal Boletín Oficial del Estado [en línea]. <https://www.boe.es/buscar/act.php?id=BOE-A-1960-10906>.

Ley 18/2007, de 28 de diciembre, del derecho a la vivienda. Noticias Jurídicas [en línea]. <http://noticias.juridicas.com/base_datos/CCAA/ca-l18-2007.html>.

Ley 4/2013, de 4 de junio, de medidas de flexibilización y fomento del mercado del alquiler de viviendas. Agencia Estatal Boletín Oficial del Estado [en línea]. <https://www.boe. es/diario_boe/txt.php?id=BOE-A-2013-5941>.

Real Decreto ley 2/1985, de 30 de abril, sobre Medidas de Política Económica. Agencia Estatal Boletín Oficial del Estado [en línea]. <https://www.boe.es/buscar/doc.php?id=BOE-A-1985-8402>. 


\section{Sitios Internet}

AJUNTAMENT DE BARCELONA, Contratos y precios registrados de las viviendas de alquiler, Año 2015 [en línea], 2016. <http://www.bcn.cat/estadistica/castella/dades/timm/ipreus/habllo/a2015/tdtel.htm>. [ 11 de junio de 2016].

AJUNTAMENT DE BARCELONA, El espacio de encuentro con la gestión de la ciudad [en línea], s/f. <http://ajuntament.barcelona.cat/es/>. [18 de noviembre de 2015]

ASOCIACIÓN 500X20 POR UN ALQUILER PÚBLICO Y ASEQUIBLE [en línea], s/f. <http://500x20.prouespeculacio.org/>. [ 8 de junio de 2016]

CONSORCI DE L'HABITATGE DE BARCELONA [en línea], Año 2016. <http://www.bcn. cat/consorcihabitatge/es/funcions.html>. [29 de mayo de 2016]

CONSORCI DE L'HABITATGE DE BARCELONA, Funciones, [en línea], Año 2016. <http:// www.bcn.cat/consorcihabitatge/es/funcions.html>. [ 1 de junio de 2016].

CONSORCI DE L'HABITATGE DE BARCELONA, Consell de l'Habitatge Social de Barcelona, [en línea], sin fecha. <http://www.bcn.cat/consorcihabitatge/es/consell-habitatge.html>. [27 de diciembre de 2016].

GENERALITAT DE CATALUNYA, Información, trámites y servicios [en línea], s/f. <http:// web.gencat.cat/es/inici/index.html>. [18 de noviembre de 2015]

GENERALITAT DE CATALUNYA, Indicador de renta de suficiencia [en línea], Año 2015. $<$ http://sac.gencat.cat/sacgencat/AppJava/servei_fitxa.jsp?codi=13844>. [7 de noviembre de 2015]

INDICADOR DE RENTA DE SUFICIENCIA DE CATALUÑA (IRSC) [en línea], Año 2016. $<$ http://sac.gencat.cat/sacgencat/AppJava/servei_fitxa.jsp?codi=13844>. [7 de junio de 2016]

INSTITUT D’ESTADÍSTICA DE CATALUNYA (IDESCAT) [en línea], 2016. Disponible en:

$<$ http://www.idescat.cat/pub/?id=aec\&n=941\&lang=es $>$. [Página consultada el 7 de junio de 2016]

INSTITUTO NACIONAL DE ESTADÍSTICA (INE) [en línea], Año 2015. <http://www.ine. es/>. [ 8 de noviembre de 2015]

INDICADOR PÚBLICO DE RENTA DE EFECTOS MÚLTIPLES (IPREM) [en línea], s/f. $<$ http://www.iprem.com.es/>. [6 de noviembre de 2015]

MINISTERIO DE EMPLEO Y SEGURIDAD SOCIAL, Seguridad Social, Glosario, Unidad Económica de Convivencia [en línea], Año 2016.<http://www.seg-social.es/Internet_1/Glosario/index.htm?ssUserText=U\#44525>. [27 de noviembre de 2016].

MINISTERIO DE FOMENTO, Organización y funciones [en línea], s/f. <http://www.fomento.gob.es/MFOM/LANG_CASTELLANO/INFORMACION_MFOM/ORGANIZACION_Y_ FUNCIONES/>. [ 12 de noviembre de 2015]

REGISTRE DE SOL-LICITANTS D'HABITATGE AMB PROTECCIÓ OFICIAL DE BARCELONA, En GENERALITAT DE CATALUNYA-AJUNTAMENT DE BARCELONA, Consorci de l'Habitatge de Barcelona [en línea], s/f. <https://w30.bcn.cat/APPS/ofhreghabitatge/paginas/ ShowPagina.do?idPagina=2>. [ 6 de noviembre de 2015] 


\section{Artículos de prensa y media}

AJUNTAMENT DE BARCELONA. " Més de nou-centes persones dormen al carrer a Barcelona» [en línea], 19 de mayo de 2016. <http://ajuntament.barcelona.cat/noubarris/ca/noticia/mzss-de-noucentes-persones-dormen-al-carrer-a-barcelona>. [26 de junio de 2016]

AJUNTAMENT DE BARCELONA. «Barcelona crea una unitat d'actuació preventiva per aturar desnonaments i lluitar contra l'exclusió residencial » [en línea], 19 de enero de 2016. $<$ http://ajuntament.barcelona.cat/premsa/2016/01/19/barcelona-crea-una-unitat-dactuacio-preventiva-per-aturar-desnonaments-i-lluitar-contra-lexclusio-residencial/>. [16 de junio de 2016]

ANGULO, Silvia y AROCA, Jaume. «El 90\% de los desahucios en Barcelona son por impago del alquiler", La Vanguardia [en línea], 16 de junio de 2014. <http://www.lavanguardia.com/economia/20140616/54409047331/desahucios-barcelona-impago-alquiler.html>. [24 de mayo de 2016]

BENAVIDES, Luis. "UCER, equipo antidesahucio », El Periódico Barcelona [en línea], 27 de abril de 2016. <http://www.elperiodico.com/es/noticias/barcelona/ucer-equipo-antidesahucio-5086972>. [26 de mayo de 2016]

VILALLONGA, Isabel. "La necesaria derogación del "decreto Boyer" de alquileres», El País [en línea], 18 de marzo de 1991. <http://elpais.com/diario/1991/03/18/madrid/669299063_850215.html>. [2 de junio de 2016]

(c) Copyright: Tania Herrera Romero, 2017

(C) Copyright Scripta Nova, 2017.

Ficha bibliográfica:

HERRERA ROMERO, Tania. La mediación como alternativa. Política de vivienda y regulación de la emergencia habitacional en Barcelona Scripta Nova. Revista Electrónica de Geografía y Ciencias Sociales. [En línea]. Barcelona: Universidad de Barcelona, 15 de mayo de 2017, vol. XXI, nº 566. ISSN: 1138-9788. 